\title{
A New Odd Fréchet Lehmann Type II-G Family of Distributions: A Power Function Distribution With Theory and Applications
}

\author{
Alya Al Mutairi ${ }^{1} \&$ Muhammad Z. Arshad ${ }^{2}$ \\ ${ }^{1}$ Department of Mathematics, Faculty of Science, Taibah University, Medina 4321, Saudi Arabia. \\ ${ }^{2}$ Department of Mathematics and Statistics, University of Agriculture, Faisalabad 54000, Pakistan. \\ Correspondence: Alya Al Mutairi, Department of Mathematics, Faculty of Science, Taibah University, Medina 4321, \\ Saudi Arabia
}

Received: December 7, 2021 Accepted: January 14, 2022 Online Published: February 13, 2022

doi:10.5539/ijsp.v11n2p29

URL: https://doi.org/10.5539/ijsp.v11n2p29

\begin{abstract}
Modeling complex random phenomena frequently observed in reliability engineering and medical science once thought to be an enigma. Scientists and practitioners agree that an appropriate but simple model is the best choice for this investigation. We contribute a new family referred to as an odd Fréchet Lehmann type-II (OFrLII) G family of distributions to address these issues. This new family has involved a shape parameter that modulated the tails of new models. Furthermore, we develop a list of eight new sub-models for a new family and a power function distribution (OFrLII-PF) nominated for detailed discussion. We derive several complementary mathematical properties and explicit expressions for the moments, quantile function, and order statistics. We plot possible shapes of the density and the hazard rate functions over the particular choices of the model parameters. We follow a technique known as maximum likelihood estimation to estimate unknown model parameters and a simulation study established to assess the asymptotic behavior of these MLEs. The applicability of the OFrLII-G family, is evaluated via OFrLII -PF distribution. For this, we fit two engineering and one COVID-19 pandemic dataset. Supportive results of OFrLII-PF distribution declare it as a better fit model against the well-established competitor's ones. A modified odd Fréchet Lehmann Type II-G Family of Distributions: A Power Function Distribution with Theory and Applications
\end{abstract}

Keywords: Lehmann type distribution, Fréchet distribution, power function distribution, COVID-19, failure rate function; moments, Entropy, maximum likelihood estimation

Mathematics Subject Classification: 60E05, 62P12, 62P30

\section{Introduction}

Over a long time, modeling complex random phenomena predominantly in reliability engineering and medical sciences consider an enigma for researchers. For this exploration, an appropriate but simple model is the first choice of scientists and practitioners. Several bounded and unbounded but simple to complex lifetime models have been developed to overcome these challenges, but a revolutionary change in the research world is attributed to [1]. The study by [1] developed one of the most spartan families known as a Lehmann type-I (L-I) with (cumulative distribution function CDF $\left[P^{a}(z)\right] . \mathrm{L}-\mathrm{I}$ was the simple exponentiated version of any arbitrary baseline model. Lehmann's work was further discussed by [2] for the exponential distribution. In the meantime, [3] proposed a new technique to generate models with $\mathrm{CDF}[P(z) /(P(z)+a \bar{P}(z))]$. Study by [4] proposed a beta generated- $P$ family with $\operatorname{CDF} F(x)=\int_{0}^{Z(x)} b(t) d t$, where $b(t)$ is the PDF of beta distribution with $G(x ; \zeta) \epsilon(0,1)$ is a CDF of any arbitrary baseline model. [5] proposed an odd $\log$ - $\operatorname{logistic}-P$ family with $\operatorname{CDF}[P(z) / \bar{P}(z)]$. [6] proposed a quadratic rank transmutation map with $\mathrm{CDF}$ $\left[(1+c) P(z)-c P^{2}(z)\right]$. [7] proposed a Kumaraswamy generalized-P family with CDF $\left[1-\left[1-P^{a}(z)\right]^{b}\right]$. [8] proposed a gamma $-P$ family with $\mathrm{CDF}[-\log P(z)]$. [9] developed a dual transformation and established a Lehmann type-II (L-II) $P$ family with $\operatorname{CDF} Z(x)=1-(1-P(z))^{a}$. [10] proposed a $T-X$ family with $\mathrm{CDF}[1-R(W[G(z)])]$. [11] proposed a Weibull- $P$ family with $\operatorname{CDF}\left[1-e^{\left(-a[P(z) / \bar{P}(z)]^{b}\right)}\right]$. [12] proposed a beta Marshall-Olkin- $P$ family with $\mathrm{CDF}\left[I_{P-M O(z)}(a, b)\right]$. [13] proposed a DUS transformation to generate new models with CDF $\left[\left(e^{P(z)}-1\right) /(e-1)\right] \cdot[14]$ proposed a Logistic-X family with $\mathrm{CDF}\left[\left[1+[-\log [\bar{P}(z)]]^{-a}\right]^{-1}\right] .[15]$ proposed an alpha transformation with $\mathrm{CDF}\left[\left(\alpha^{P(z)}-1\right) /(\alpha-1)\right]$. [16] developed an odd Fréchet (OFré)-G family with CDF is given by 
$Z(x)=\mathrm{e}^{-\left[\frac{1-G(z)}{G(z)}\right]^{a}} .[17]$ proposed a new alpha power transformation with $\operatorname{CDF}\left[P(z) \alpha^{P(z)} / \alpha\right]$. Study by [18] proposed another technique with $\operatorname{CDF}\left[\left(a^{P(z)}-e^{P(z)}\right) /(a-e)\right]$ to generate new models. [19] proposed a Gull alpha power Weibull-P family with $\operatorname{CDF}\left[\alpha P(z) / \alpha^{P(z)}\right]$. [20] proposed a new Kumaraswamy-P family with $\operatorname{CDF}[1-[1-$ $\left.\left.\left(1-\bar{P}(z)^{P(z)}\right)^{a}\right]^{b}\right]$. [21] proposed a new logarithmic-P family with $\mathrm{CDF}[1-\log [(2-\lambda P(z)) / \log (2)]]$ and many others. Attracted features of L-I,-II compelled the researchers to explore new areas for modeling and discuss the hidden characteristics of classical and modified models. For recent examples, see the latest work of the references. [22] generalized a new model via L-II- $P$ family. [23] discussed exponentiated PF distribution with L-I. [24] developed a generalized version of L-II. [25] developed the $P$ family of a generalized version of L-II with CDF $\left[1-((1-P(z)) /(1-a P(z)))^{b}\right]$, and [26] discussed a beta version of L-II with CDF $\left[I_{1-(1-P(z))^{a}}(a, b)\right]$.

\subsection{Definition}

We have proposed a new family, known as odd Fréchet Lehmann type-II (OFrLII) G family of distributions with CDF

$$
F_{\mathrm{O} F \mathrm{LII}-G}(x ; \phi)=1-\left(1-e^{-\left(\frac{1-G(x ; \phi)}{G(x ; \phi)}\right)}\right)^{a} ; x \in \mathbb{R}, a, \phi>0,
$$

where $G(x ; \phi) \epsilon(0,1)$ is a CDF of any arbitrary baseline model based on the parametric vector $\phi$ depends on $(r \times 1)$ with $a>0$ as a shape parameter. OFrLII $-\mathrm{G}$ family is obtained by replacing the CDF of L-II with the CDF of the OFré - $\mathrm{G}$ family withholding a power parameter of the OFré $-\mathrm{G}$ family, which equals one.

In Table 1 we present eight new sub-models survival functions $S(x ; \phi)$ corresponding to classical baseline models $G(x ; \phi)$.

Table 1. List of New Sub-models $S(x ; \phi)$ corresponding to $G(x ; \phi)$ functions

\begin{tabular}{lllll}
\hline Model & Support & Baseline model & Survival models & $\boldsymbol{\phi}$ \\
\hline Rayleigh & $(0, \infty)$ & $1-e^{-b x^{2}}$ & $\left(1-e^{1-\left(1-e^{-b x^{2}}\right)^{-1}}\right)^{a}$ & $a, b$ \\
\hline Gompertz & $(0, \infty)$ & $1-e^{-b\left(e^{c x}-1\right)}$ & $\left(1-e^{\left.1-\left(1-e^{-b\left(e^{c x}-1\right)}\right)^{-1}\right)^{a}}\right.$ & $a, b, c$ \\
\hline Pareto & $(m, \infty)$ & $1-\left(\frac{m}{x}\right)^{b}$ & $\left(1-e^{1-\left(1-\left(\frac{m}{x}\right)^{b}\right)^{-1}}\right)^{a}$ & $a, b$ \\
\hline Fréchet & $(0, \infty)$ & $e^{-b x^{-c}}$ & $\left(1-e^{\left.1-\left(e^{-b x^{-c}}\right)^{-1}\right)^{a}}\right.$ & $a, b, c$ \\
\hline Burr-X & $(0, \infty)$ & $\left(1-e^{\left.-(b x)^{2}\right)^{c}}\right.$ & $\left(1-e^{\left.1-\left(1-e^{-(b x)^{2}}\right)^{-c}\right)^{a}}\right.$ & $a, b, c$ \\
\hline Weibull & $(0, \infty)$ & $1-e^{-b x^{c}}$ & $\left(1-e^{1-\left(1-e^{-b x^{c}}\right)^{-1}}\right)^{a}$ & $a, b, c$ \\
\hline Lomax & $(0, \infty)$ & $1-\left(1+x b^{-1}\right)^{-c}$ & $\left(1-e^{1-\left(1-\left(1+x b^{-1}\right)^{-c}\right)^{-1}}\right)^{a}$ & $a, b, c$ \\
\hline Power Function & $\left(0, \mathrm{~g}_{0}\right)$ & $\left(\frac{x}{\mathrm{~g}_{0}}\right)^{b}$ & $\left(1-e^{1-\left(\frac{\mathrm{g}_{0}}{x}\right)^{b}}\right)^{a}$ & $a, b$
\end{tabular}

Let $\mathrm{g}(x ; \phi)=d G(x ; \phi) / d x$ is the probability density function (PDF) of any baseline model. The associated $\operatorname{PDF}\left(f_{\mathrm{OFrLII}-G}(x ; \phi)\right)$, hazard rate function $\operatorname{HRF}\left(h_{\mathrm{OFrLII}-G}(x ; \phi)\right)$, and quantile function $\left(Q_{\mathrm{OFrLII}-G}(q ; \phi)\right)$ corresponding to $\mathrm{O} F r$ LII-G family are, given by, respectively

$$
f_{\text {OFrLII-G }}(x ; \phi)=\frac{a g(x ; \phi)}{G^{2}(x ; \phi)} e^{-\left(\frac{1-G(x ; \phi)}{G(x ; \phi)}\right)}\left(1-e^{-\left(\frac{1-G(x ; \phi)}{G(x ; \phi)}\right)}\right)^{a-1},
$$




$$
h_{\mathrm{OFrLII-G}}(x ; \phi)=\frac{a \mathrm{~g}(x ; \phi) e^{-\left(\frac{1-G(x ; \phi)}{G(x ; \phi)}\right)}}{G^{2}(x ; \phi)\left(1-e^{-\left(\frac{1-G(x ; \phi)}{G(x ; \phi)}\right)}\right)},
$$

and

$$
Q_{\mathrm{OFrLII}-G}(q ; \phi)=G^{-1}\left(1-\log \left(1-(1-q)^{\frac{1}{a}}\right)\right)^{-1}, q \in(0,1) .
$$

Now and onward, an odd Fréchet Lehmann type-II (OFrLII) G family random variable $X$ corresponding to $f_{\mathrm{OFrLII}-G}(x ; \phi)$ will be denoted by $X \sim \mathrm{O} F r$ LII $-G(x ; \phi)$ and to the best of our knowledge, no study has been done in the past that relates to our new family. This study has the following motivations:

(i) To propose a new family that generates flexibility and improves the features of baseline models.

(ii) Closed-form features of CDF, PDF and HRF of new models are simple to interpret.

(iii) New models offer greater distributional flexibility in terms of high kurtosis.

(iv) It offers a better fit over the asymmetric, and bathtub-shaped random phenomena particularly associated with the engineering, and medical sciences events.

This paper is assembled on the following steps. The construction of a new family is discussed in Section 1. General characteristics of a new family are developed in Section 2. A detailed discussion of OFrLII-PF distribution (sub-model) is done in Section 3. A technique to estimate the model parameters named maximum likelihood estimation and a simulation study are discussed in Section 4. Real-life data sets are analyzed in Section 6 and finally, the conclusion is reported in Section 7.

\section{General Characteristics}

\subsection{Useful Representation}

Linear representation of CDF and PDF has a significant role in providing more ease for complex mathematical measures. For OFrLII-G family we utilize binomial and exponential series expansions and it is given by

$$
(1-z)^{\beta}=\sum_{i=0}^{\infty}(-1)^{i}\left(\begin{array}{c}
\beta \\
i
\end{array}\right) z^{i},|z|<1 ; \quad e^{z}=\sum_{j=0}^{\infty} \frac{z^{j}}{j !} .
$$

Infinite linear combinations of CDF

$$
\begin{gathered}
F_{\mathrm{OFrLII}-G}(x ; \phi)=1-\sum_{i, j, k=0}^{\infty}\left(\begin{array}{l}
a \\
i
\end{array}\right)\left(\begin{array}{l}
j \\
k
\end{array}\right) \frac{(-1)^{i+j+k} i^{j}}{j !} G^{k-j}(x ; \phi), \\
F_{\mathrm{O} F r \mathrm{LII}-G}(x ; \phi)=1-\sum_{i, j, k=0}^{\infty} \Delta_{i, j, k} G^{c}(x ; \phi),
\end{gathered}
$$

and PDF for OFrLII-G family are given by

$$
\begin{gathered}
f_{\mathrm{OF} r \mathrm{LII}-G}(x ; \phi)=a \sum_{i, j, k, l, m=0}^{\infty}\left(\begin{array}{l}
i \\
j
\end{array}\right)\left(\begin{array}{c}
a-1 \\
k
\end{array}\right)\left(\begin{array}{c}
l \\
m
\end{array}\right) \frac{(-1)^{i+j+k+l+m}}{i ! l !} \mathrm{g}(x ; \phi) G^{j-i-l+m-2}(x ; \phi), \\
f_{\mathrm{O} F r \mathrm{LII}-G}(x ; \phi)=a \sum_{i, j, k=0}^{\infty} \nabla_{i, j, k, l, m} \mathrm{~g}(x ; \phi) G^{d}(x ; \phi),
\end{gathered}
$$

respectively, where $\Delta_{i, j, k}=\left(\begin{array}{c}a \\ i\end{array}\right)\left(\begin{array}{l}j \\ k\end{array}\right) \frac{(-1)^{i+j+k_{i} j}}{j !}, c=k-j, \nabla_{i, j, k, l, m}=\left(\begin{array}{c}i \\ j\end{array}\right)\left(\begin{array}{c}a-1 \\ k\end{array}\right)\left(\begin{array}{c}l \\ m\end{array}\right) \frac{(-1)^{i+j+k+l+m}}{i ! l !}, d=j-i-l+$ 
$m-2$. The expansions in (5) and (6) provide us the exponentiated-G (Exp-G) family which is quite useful for the generalization of models.

2.2 Moments

The $r$-th ordinary moment $\left(\right.$ say $\left.\mu_{r}^{\prime}\right)$ of $X$ is given by

$$
\mu_{r}^{\prime}=\int_{-\infty}^{+\infty} x^{r} f(x) d x
$$

By following (6), we obtain

$$
\mu_{r-\mathrm{OFr \textrm {LII } - G}}^{\prime}=a \sum_{i, j, k, l, m=0}^{\infty} \nabla_{i, j, k, l, m} I_{d}^{r}(x ; \phi),
$$

where

coefficient

$$
\nabla_{i, j, k, l, m}=\left(\begin{array}{c}
i \\
j
\end{array}\right)\left(\begin{array}{c}
a-1 \\
k
\end{array}\right)\left(\begin{array}{c}
l \\
m
\end{array}\right) \frac{(-1)^{i+j+k+l+m}}{i ! l !}, d=j-i-l+m-2
$$

$I_{d}^{r}(x ; \phi)=\int_{-\infty}^{+\infty} x^{r} \mathrm{~g}(x ; \phi) G^{d}(x ; \phi) d x$.

\subsection{Incomplete Moments}

The first incomplete moment has a significant role in the discussion of Bonferroni and Lorenz curves. The $r$ - th incomplete moments $\varphi_{r}(t)=\int_{-\infty}^{t} x^{r} f(x) d x$ directly followed by (7) are given by

$$
\varphi_{r-\mathrm{O} F r \mathrm{LII}-\mathrm{G}}(t ; \phi)=a \sum_{i, j, k, l, m=0}^{\infty} \nabla_{i, j, k, l, m} I^{r, t}{ }_{d}(x ; \phi),
$$

where $I^{r, t}{ }_{d}(x ; \phi)=\int_{-\infty}^{t} x^{r} \mathrm{~g}(x ; \phi) G^{d}(x ; \phi) d x$. For parent distributions, integrals $I_{d}^{r}(x ; \phi)$ and $I^{r, t}{ }_{d}(x ; \phi)$ can be solved numerically.

\subsection{Residual and Reversed Residual Life Functions}

The residual life function is defined by $R_{t}(x)=\frac{S(x+t)}{S(t)}$. The residual life function of $X$ is given by

$$
R_{t-\mathrm{OFrLII-G}}(x)=\frac{\left(1-e^{-\left(\frac{1-G(x+t ; \phi)}{G(x+t ; \phi)}\right)}\right)^{a}}{\left(1-e^{-\left(\frac{1-G(t ; \phi)}{G(t ; \phi)}\right)}\right)^{a}} .
$$

Furthermore, reversed residual life function is defined by $\bar{R}_{t}(x)=\frac{S(x-t)}{S(t)}$. The reversed residual life function of $X$ is given by

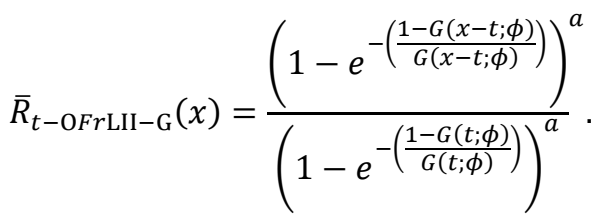

\subsection{Moment Generating Function}

Moment generating function $M_{X}(t)$ is defined as $M_{X}(t)=\sum_{r=0}^{\infty} \frac{t^{r}}{r !} \mu_{r}^{\prime}$ and it is given by 


$$
M_{X-\mathrm{O} F r \mathrm{LII}-G}(x ; \phi)=a \sum_{r=0}^{\infty} \frac{t^{r}}{r !} \sum_{i, j, k=0}^{\infty} \nabla_{i, j, k, l, m} I_{d}^{r}(x ; \phi),
$$

where coefficient

$$
\nabla_{i, j, k, l, m}=\left(\begin{array}{c}
i \\
j
\end{array}\right)\left(\begin{array}{c}
a-1 \\
k
\end{array}\right)\left(\begin{array}{c}
l \\
m
\end{array}\right) \frac{(-1)^{i+j+k+l+m}}{i ! l !}, d=j-i-l+m-2
$$

and

$$
I_{d}^{r}(x ; \phi)=\int_{-\infty}^{+\infty} x^{r} \mathrm{~g}(x ; \phi) G^{d}(x ; \phi) d x
$$

\subsection{Entropy}

When a system is quantified by randomness in general, it is known as entropy. [27] entropy of $X$ is given by

$$
H_{\delta}(X)=\frac{1}{1-\delta} \log \int_{-\infty}^{\infty} f^{\delta}(x) d x, \quad \delta>0 \text { and } \delta \neq 1 .
$$

By following (2), we simplify $f(x ; \phi)$ in terms of $f^{\delta}(x ; \phi)$, we get

$$
f^{\delta}{ }_{\text {OFrLII-G }}(x ; \phi)=\frac{a^{\delta} \mathrm{g}^{\delta}(x ; \phi)}{G^{2 \delta}(x ; \phi)} e^{-\delta\left(\frac{1-G(x ; \phi)}{G(x ; \phi)}\right)}\left(1-e^{-\left(\frac{1-G(x ; \phi)}{G(x ; \phi)}\right)}\right)^{\delta(a-1)} .
$$

The expansion of $e^{-\delta\left(\frac{1-G(x ; \phi)}{G(x ; \phi)}\right)}$ and $\left(1-e^{-\left(\frac{1-G(x ; \phi)}{G(x ; \phi)}\right)}\right)^{\delta(a-1)}$ provide us Exp-G and the last expression can be written as follows

$$
f_{\text {OFrLII-G }}^{\delta}(x ; \phi)=\left(\begin{array}{c}
\frac{a^{\delta} \mathrm{g}^{\delta}(x ; \phi)}{G^{2 \delta}(x ; \phi)} \sum_{i=0}^{\infty} \frac{(-1)^{i} \delta^{i}}{i !} \times \frac{1}{G^{i}(x ; \phi)} \sum_{j=0}^{\infty}\left(\begin{array}{c}
i \\
j
\end{array}\right)(-1)^{j} G^{j}(x ; \phi) \times \\
\sum_{k=0}^{\infty}\left(\begin{array}{c}
\delta(a-1) \\
k
\end{array}\right)(-1)^{k} \sum_{l=0}^{\infty} \frac{(-1)^{l} k^{l}}{l !} \times \frac{1}{G^{l}(x ; \phi)} \sum_{m=0}^{\infty}\left(\begin{array}{c}
l \\
m
\end{array}\right)(-1)^{m} G^{m}(x ; \phi)
\end{array}\right) .
$$

Now place the last information in (9) which provides us a reduced form of Rényi entropy for $X$ and it is given as follows

$$
H_{\delta-\mathrm{OFrLII}-G}(X)=\frac{1}{1-\delta} \log a^{\delta} \sum_{i, j, k, l, m=0}^{\infty} \nabla_{i, j, k, l, m}^{*} I_{d}^{\delta}(x ; \phi),
$$

where

$\nabla_{i, j, k, l, m}^{*}=\left(\begin{array}{c}i \\ j\end{array}\right)\left(\begin{array}{c}\delta(a-1) \\ k\end{array}\right)\left(\begin{array}{c}l \\ m\end{array}\right) \frac{(-1)^{i+j+k+l+m} \delta^{i} k^{l}}{i ! l !}, d=j-i-l+m-2 \delta, I_{d}^{\delta}(x ; \phi)=\int_{-\infty}^{+\infty} \mathrm{g}^{\delta}(x ; \phi) G^{d}(x ; \phi) d x$.

\subsection{Distribution of Order Statistics}

Let $X_{1}, X_{2}, \ldots, X_{n}$ be a random sample of size $n$ follows to the 0 FrLII-G family and $X_{(1: n)}<X_{(2: n)}<\ldots<X_{(n: n)}$ be the corresponding order statistics. The PDF of $X_{(i)}$ is given by

$$
f_{(i: n)}(x ; \phi)=\frac{1}{B(i, n-i+1) !}(F(x ; \phi))^{i-1}(1-F(x ; \phi))^{n-i} f(x ; \phi), i=1,2,3, \ldots n .
$$

Using the fact that

$$
(1-F(x ; \phi))^{n-i}=\sum_{m=0}^{n-i}(-1)^{m}\left(\begin{array}{c}
n-i \\
m
\end{array}\right) F(x ; \phi)^{m},
$$

and place the last information in $f_{(i: n)}(x ; \phi)$, we obtain the most refined form of OS PDF and expression may be written as follows

$$
f_{(i: n)}(x ; \phi)=\frac{f(x ; \phi)}{B(i, n-i+1) !} \sum_{m=0}^{n-i}(-1)^{m}\left(\begin{array}{c}
n-i \\
m
\end{array}\right) F(x ; \phi)^{i+m-1}
$$


$F(x ; \phi)$, and $f(x ; \phi)$ are the associated CDF with the corresponding PDF of the $\mathrm{O}-\mathrm{L}-\mathrm{II}-\mathrm{G}$ family and

$$
F(x ; \phi)^{i+m-1}=\sum_{i, j, k, l, o=0}^{\infty}\left(\begin{array}{c}
n-i \\
m
\end{array}\right)\left(\begin{array}{c}
i+m-1 \\
j
\end{array}\right)\left(\begin{array}{l}
j \\
k
\end{array}\right)\left(\begin{array}{l}
l \\
o
\end{array}\right) \frac{(-1)^{j+k+l+m+o}}{l !} k^{l} G^{o-l}(x ; \phi) .
$$

Hence one may obtain the straightforward expression of OS PDF by inserting the last information in (10).

\subsection{Bivariate Extension}

In this sub-section, we present a simple bivariate extension of the OFrLII-G family. A joint CDF of the OFrLII family is given by

$$
F_{O-L-I I-G}(x, y ; \phi)=1-\left(1-e^{-\left(\frac{1-G(x, y ; \phi)}{G(x, y ; \phi)}\right)}\right)^{a}, x, y \in \mathbb{R}, a, \phi>0,
$$

where $G(x, y ; \phi)$ is a bivariate continuous distribution function along with marginal CDF's $G_{1}(x ; \phi)$ and $G_{2}(y ; \phi)$. We refer to it as a bivariate OFrLII-G family of distributions. The marginal CDF's of $X$ and $Y$ is given by respectively are given by

$$
\begin{aligned}
& F_{X-\mathrm{O} F \mathrm{LII}-G}(x ; \phi)=1-\left(1-e^{-\left(\frac{1-G_{1}(x ; \phi)}{G_{1}(x ; \phi)}\right)}\right)^{a}, \\
& F_{Y-\mathrm{O} F r \mathrm{LII}-G}(y ; \phi)=1-\left(1-e^{-\left(\frac{1-G_{2}(y ; \phi)}{G_{2}(y ; \phi)}\right)}\right)^{a} .
\end{aligned}
$$

The joint PDF of $(X, Y)$ can be determined easily by following $f_{X, Y}(x, y ; \phi)=\frac{\partial^{2} F_{X, Y}(x, y)}{\partial x \partial y}$. Furthermore, the marginal PDFs of $\mathrm{X}$ and $\mathrm{Y}$ are given by, respectively

$$
\begin{aligned}
& f_{O-L-I I-G-X}(x ; \phi)=\frac{a g_{1}(x ; \phi)}{G^{2}(x ; \phi)} e^{-\left(\frac{1-G_{1}(x ; \phi)}{G_{1}(x ; \phi)}\right)}\left(1-e^{-\left(\frac{1-G_{1}(x ; \phi)}{G_{1}(x ; \phi)}\right)}\right)^{a-1}, \\
& f_{O-L-I I-G-Y}(y ; \phi)=\frac{a \mathrm{~g}_{2}(y ; \phi)}{G^{2}{ }_{2}(y ; \phi)} e^{-\left(\frac{1-G_{2}(y ; \phi)}{G_{2}(y ; \phi)}\right)}\left(1-e^{-\left(\frac{1-G_{2}(y ; \phi)}{G_{2}(; \phi)}\right)}\right)^{a-1} .
\end{aligned}
$$

The conditional CDFs of $X$ and $Y$ are given by, respectively

$$
\begin{aligned}
& F_{(X / Y)-\mathrm{O} F r \mathrm{LII}-\mathrm{G}}(x / y ; \phi)=\frac{1-\left(1-e^{-\left(\frac{1-G(x, y ; \phi)}{G(x, y ; \phi)}\right)}\right)^{a}}{1-\left(1-e^{-\left(\frac{1-G_{2}(y ; \phi)}{G_{2}(y ; \phi)}\right)}\right)^{a}}, \\
& F_{(Y / X)-\mathrm{O} F r \mathrm{LII}-\mathrm{G}}(y / x ; \phi)=\frac{1-\left(1-e^{-\left(\frac{1-G(x, y ; \phi)}{G(x, y ; \phi)}\right)}\right)^{a}}{1-\left(1-e^{-\left(\frac{1-G_{1}(x ; \phi)}{G_{1}(x ; \phi)}\right)}\right)^{a}} \text {. }
\end{aligned}
$$

\subsection{Inference}

In this sub-section, we estimate unknown parameters of the $\mathrm{OFrLII}-\mathrm{G}$ family with the assistance of maximum likelihood estimation and the ordinary least square method.

2.9.1 Maximum Likelihood Estimation (MLE)

Let $x_{1}, x_{2}, x_{3}, \ldots, x_{n}$ be a random sample of size $n$ from the $\mathrm{O} F r$ LII-G family, then the log-likelihood function $\log L$ $=\log L(\phi)$ is given by 


$$
\begin{aligned}
& \log L_{\mathrm{OFrLII}-\mathrm{G}}=n \log a+\sum_{i=1}^{n} \log \left(\mathrm{g}\left(x_{i} ; \phi\right)\right)-2 \sum_{i=1}^{n} \log G\left(x_{i} ; \phi\right)+\sum_{i=1}^{n}\left(\frac{1-G\left(x_{i} ; \phi\right)}{G\left(x_{i} ; \phi\right)}\right) \\
& +(a-1) \sum_{i=1}^{n} \log \left(1-e^{-\left(\frac{1-G\left(x_{i} ; \phi\right)}{G\left(x_{i} ; \phi\right)}\right)}\right) .
\end{aligned}
$$

The partial derivatives of $\log L_{\mathrm{OFrLII}-\mathrm{G}}=l$ for $a$ and $\phi$ are

$$
\begin{gathered}
\frac{\partial l}{\partial a}=\frac{n}{a}+\sum_{i=1}^{n} \log \left(1-e^{-\left(\frac{1-G\left(x_{i} ; \phi\right)}{G\left(x_{i} ; \phi\right)}\right)}\right), \\
\frac{\partial l}{\partial \phi}=\sum_{i=1}^{n} \frac{\mathrm{g}^{\prime}{ }_{\phi}\left(x_{i} ; \phi\right)}{\mathrm{g}\left(x_{i} ; \phi\right)}-2 \sum_{i=1}^{n} \frac{G^{\prime}{ }_{\phi}\left(x_{i} ; \phi\right)}{G\left(x_{i} ; \phi\right)}+\sum_{i=1}^{n} \frac{G^{\prime}{ }_{\phi}\left(x_{i} ; \phi\right)}{G^{2}\left(x_{i} ; \phi\right)}+(a-1) \sum_{i=1}^{n} \frac{G^{\prime}{ }_{\phi}\left(x_{i} ; \phi\right) e^{-\left(\frac{1-G(x ; \phi)}{G(x ; \phi)}\right)}}{G^{2}\left(x_{i} ; \phi\right)\left(1-e^{-\left(\frac{1-G(x ; \phi)}{G(x ; \phi)}\right)}\right)},
\end{gathered}
$$

respectively, where $\mathrm{g}_{\phi}{ }_{\phi}\left(x_{i} ; \phi\right)=\partial \mathrm{g}\left(x_{i} ; \phi\right) / \partial \phi$ and $G^{\prime}{ }_{\phi}\left(x_{i} ; \phi\right)=\partial G\left(x_{i} ; \phi\right) / \partial \phi$. By substituting $\partial l / \partial a$ and $\partial l / \partial \phi$ equal to zero and to obtain ML estimators $\hat{\zeta}=(\hat{a}, \hat{\phi})^{T}$ of $\zeta=(a, \phi)$, we solve these equations simultaneously. As per the prior expressions are not in closed form. Hence, $\mathrm{R}$ software will be a better choice to find out its numerical study by using any iterative methods.

\subsubsection{Ordinary Least Square (OLS)}

Let $x_{1}, x_{2}, x_{3}, \ldots, x_{n}$ be a random sample of size $n$ from the $\mathrm{O} F r$ LII-G family, then the expectation of the empirical $\mathrm{CDF}$ is known as OLS estimates and it is given by $E\left(F_{\mathrm{O} F \mathrm{LII}-G}(x ; \phi)\right)=\frac{j}{n+1} ; j=1,2,3, \ldots, n$. OLS estimates of unknown parameters $(a, \phi)$ can be obtained by maximizing the $A(x ; \phi)=\left(E\left(F_{\text {OFrLII-G }}(x ; \phi)\right)-\frac{j}{n+1}\right)^{2}$ by taking the partial derivatives $\partial A(x ; \alpha) / \partial \alpha$ and $\partial A(x ; \phi) / \partial \phi$.

\section{A New Odd Lehmann type-II Power Function (OFrLII-PF) Distribution}

In this section, we derive several explicit expressions for a sub-model of the OFrLII-G family, known as an odd Lehmann type-II power function (OFrLII-PF) distribution. For this, we have the CDF and PDF of power function as

$$
G_{P F}(x ; b)=\left(\frac{x}{g_{0}}\right)^{b}
$$

and

$$
\mathrm{g}_{P F}(x ; b)=\frac{b}{\left(\mathrm{~g}_{0}\right)^{b}} x^{b-1} ; b>0,0<x<\mathrm{g}_{0},
$$

respectively. Henceforth, the analytical expressions for CDF, PDF, and HRF of OFrLII-PF distribution are given by respectively

$$
\begin{gathered}
F_{\mathrm{O} F r \mathrm{LII}-P F}(x ; a, b)=1-\left(1-e^{1-\left(\frac{\mathrm{g}_{0}}{x}\right)^{b}}\right)^{a}, \\
f_{\mathrm{O} F r \mathrm{LII}-P F}(x ; a, b)=\frac{a b\left(\mathrm{~g}_{0}\right)^{b}}{x^{1+b}} e^{1-\left(\frac{\mathrm{g}_{0}}{x}\right)^{b}}\left(1-e^{1-\left(\frac{\mathrm{g}_{0}}{x}\right)^{b}}\right)^{a-1},
\end{gathered}
$$




$$
h_{\mathrm{O} F \mathrm{LII}-P F}(x ; a, b)=\frac{a b\left(\mathrm{~g}_{0}\right)^{b} e^{1-\left(\frac{\mathrm{g}_{0}}{x}\right)^{b}}}{\left(x^{1+b}\right)\left(1-e^{1-\left(\frac{\mathrm{g}_{0}}{x}\right)^{b}}\right)}
$$

where $0<x<\mathrm{g}_{0}$, and $a, b>0$ are two shape parameters.

\subsection{Shapes of Density and Hazard Rate Functions}

In this sub-section, several curves of PDF and HRF for $X$ at different choices of model parameters are sketched out in Figure 1. Note that PDFs ( $a$ and $b$ ) curves have increasing, decreasing, symmetric, upside down, and bathtub shapes. However, HRF's $(c$ and $d$ ) possess upside-down increasing, U-shaped, bathtub-shaped, and increasing curves.

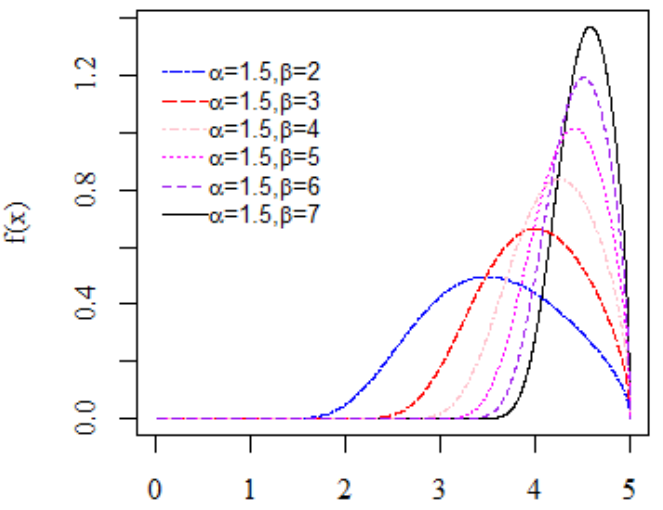

(a)

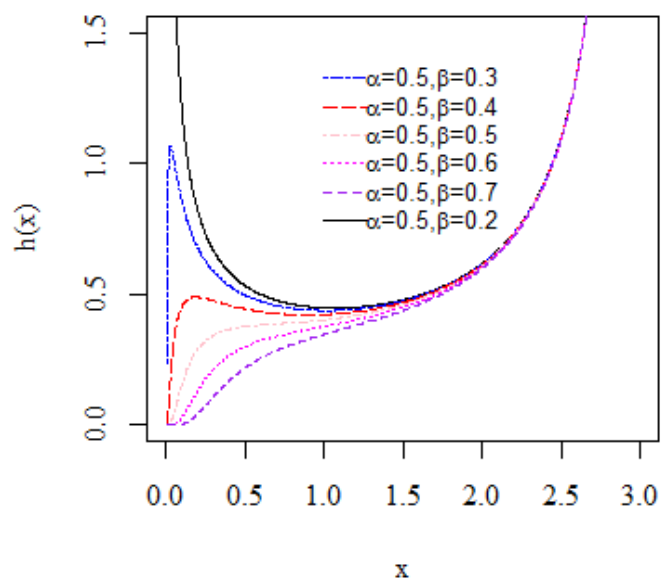

(c)

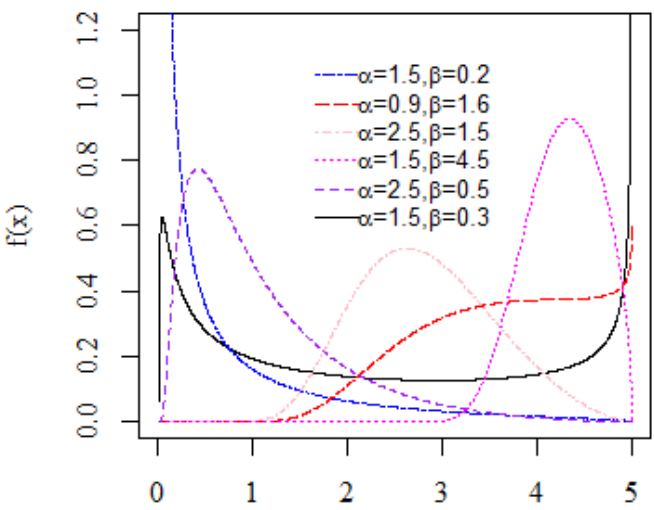

(b)

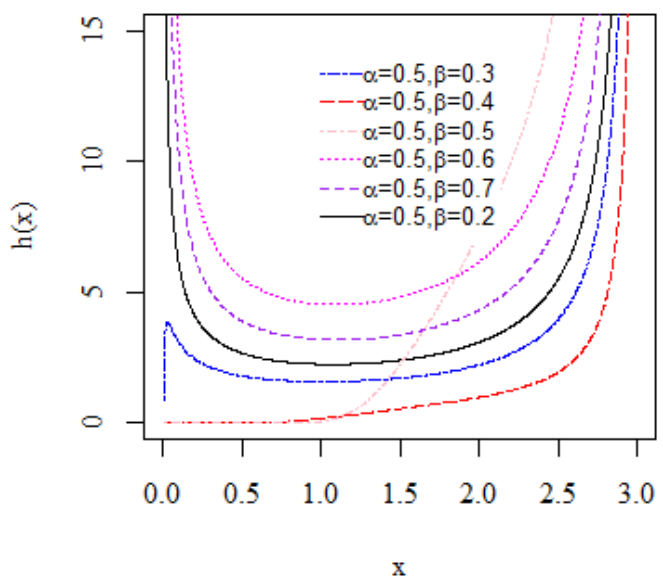

(d)

Figure 1. Different curves of density and hazard rate functions

\subsection{Useful Expansions}

Infinite linear combinations of $\mathrm{CDF}$ 


$$
\begin{gathered}
F_{\mathrm{OFrLII}-P F}(x ; a, b)=1-\sum_{i, j=0}^{\infty}\left(\begin{array}{c}
a \\
i
\end{array}\right) \frac{(-1)^{i+j} e^{j} i^{j}\left(\mathrm{~g}_{0}\right)^{b j}}{j !} x^{-b j} . \\
F_{O-L-I I-P F}(x ; a, b)=1-\sum_{i, j=0}^{\infty} A_{i, j} x^{-b j}
\end{gathered}
$$

and PDF for $X$ is given by

$$
\begin{gathered}
f_{\mathrm{O} F r \mathrm{LII}-P F}(x ; a, b)=a b \sum_{i, j, k=0}^{\infty}\left(\begin{array}{c}
a-1 \\
j
\end{array}\right) \frac{(-1)^{i+j+k} e^{1+j}\left(\mathrm{~g}_{0}\right)^{b(i+k+1)}}{i ! k !} x^{-b(i+k+1)-1}, \\
f_{\mathrm{O} F r \mathrm{LI}-P F}(x ; a, b)=a b \sum_{i, j, k=0}^{\infty} B_{i, j, k} x^{-b(i+k+1)-1},
\end{gathered}
$$

where $A_{i, j}=\left(\begin{array}{c}a \\ i\end{array}\right) \frac{(-1)^{i+j} e^{j_{i} j}\left(\mathrm{~g}_{0}\right)^{b j}}{j !}, B_{i, j, k}=\left(\begin{array}{c}a-1 \\ j\end{array}\right) \frac{(-1)^{i+j+k} e^{1+j}\left(\mathrm{~g}_{0}\right)^{b(i+k+1)}}{i ! k !}$.

\subsection{Moments}

The $r$-th ordinary moments for $X$ is defined as

$$
\mu_{r-\mathrm{O} F r \mathrm{LII}-P F}^{\prime}=a b \int_{0}^{\mathrm{g}_{0}} x^{r} \frac{\left(\mathrm{g}_{0}\right)^{b}}{x^{1+b}} e^{1-\left(\frac{\mathrm{g}_{0}}{x}\right)^{b}}\left(1-e^{1-\left(\frac{\mathrm{g}_{0}}{x}\right)^{b}}\right)^{a-1} d x,
$$

and after few simplifications we obtain

$$
\mu_{r-\mathrm{O} F \mathrm{LII}-P F}^{\prime}=a b \sum_{i, j, k=0}^{\infty} B_{i, j, k} \int_{0}^{\mathrm{g}_{0}} x^{r-b(i+k+1)-1} d x .
$$

Hence, the $r$-th ordinary moments are obtained by solving the last integral and it is given by

$$
\mu_{r-\mathrm{OFrLII}-P F}^{\prime}=a b \sum_{i, j, k=0}^{\infty} B_{i, j, k} \frac{\left(\left(\mathrm{g}_{0}\right)^{r-\chi_{b, i, k}}\right)}{r-\chi_{b, i, k}},
$$

where $B_{i, j, k}=\left(\begin{array}{c}a-1 \\ j\end{array}\right) \frac{(-1)^{i+j+k} e^{1+j}\left(\mathrm{~g}_{0}\right)^{b(i+k+1)}}{i ! k !}, \chi_{b, i, k}=b(i+k+1)$.

The derived expression in (16) is quite useful in the development of several statistical measures. For instance: to deduce the mean and negative moments of $X$, substitute $r=1$ and $r=-w$ with (16), respectively, and it is given by

$$
\mu_{1-\mathrm{OFrLII}-P F}^{\prime}=a b \sum_{i, j, k=0}^{\infty} B_{i, j, k} \frac{\left(\left(\mathrm{g}_{0}\right)^{1-\chi_{b, i, k}}\right)}{1-\chi_{b, i, k}},
$$

and

$$
\mu_{-w-\mathrm{O} F \mathrm{LII}-P F}^{\prime}=a b \sum_{i, j, k=0}^{\infty} B_{i, j, k} \frac{\left(\left(\mathrm{g}_{0}\right)^{-\left(w+\chi_{b, i, k}\right)}\right)}{1-\chi_{b, i, k}} .
$$

Furthermore, for fractional positive and fractional negative moments for $X$, substitute $r=(\mathrm{m} / \mathrm{n})$ and $r=-(\mathrm{m} / \mathrm{n})$ with (16), respectively, and the expressions are, respectively, given by

$$
\mu_{(m / n)-\mathrm{O} F r \mathrm{LII}-P F}^{\prime}=a b \sum_{i, j, k=0}^{\infty} B_{i, j, k} \frac{\left(\left(\mathrm{g}_{0}\right)^{(m / n)-\chi_{b, i, k}}\right)}{1-\chi_{b, i, k}},
$$


and

$$
\mu_{-(m / n)-\mathrm{OFrLII}-P F}^{\prime}=a b \sum_{i, j, k=0}^{\infty} B_{i, j, k} \frac{\left(\left(\mathrm{g}_{0}\right)^{-(m / n)-\chi_{b, i, k}}\right)}{1-\chi_{b, i, k}} .
$$

The moment generating function $M_{X}(t)$ is defined as $M_{X}(t)=\sum_{r=0}^{\infty} \frac{t^{r}}{r !} \mu_{r}^{\prime}$. It is obtained for $X$ as

$$
M_{X-\mathrm{O} F \mathrm{LII}-P F}(t)=a b \sum_{r=0}^{\infty} \frac{t^{r}}{r !} \sum_{i, j, k=0}^{\infty} B_{i, j, k} \frac{\left(\left(\mathrm{g}_{0}\right)^{r-\chi_{b, i, k}}\right)}{r-\chi_{b, i, k}} .
$$

The characteristic function of $X$ is defined as $\emptyset_{X}(t)=\sum_{r=0}^{\infty} \frac{(i t)^{r}}{r !} \mu_{r}^{\prime}$. It is obtained for $X$ as

$$
\emptyset_{X-\mathrm{OFrLII}-P F}(t)=a b \sum_{r=0}^{\infty} \frac{(i t)^{r}}{r !} \sum_{i, j, k=0}^{\infty} B_{i, j, k} \frac{\left(\left(\mathrm{g}_{0}\right)^{r-\chi_{b, i, k}}\right)}{r-\chi_{b, i, k}} .
$$

The factorial generating function is defined as $F_{x}(t)=E(1+t)^{x}=E\left(e^{x \ln (1+t)}\right)=\sum_{r=0}^{\infty} \frac{(\ln (1+t))^{r}}{r !} \mu_{r}^{\prime}$. It is obtained for $X$ as

$$
F_{x-\mathrm{O} F r \mathrm{LII}-P F}(t)=a b \sum_{r=0}^{\infty} \frac{(\ln (1+t))^{r}}{r !} \sum_{i, j, k=0}^{\infty} B_{i, j, k} \frac{\left(\left(\mathrm{g}_{0}\right)^{r-\chi_{b, i, k}}\right)}{r-\chi_{b, i, k}}
$$

The Mellin transformation is defined $\operatorname{as}_{x}(m)=\int_{0}^{\infty} x^{m-1} f(x) d x$. It is obtained for $X$ as

$$
M_{x-\mathrm{O} F r \mathrm{LII}-P F}(m)=a b \sum_{i, j, k=0}^{\infty} B_{i, j, k} \frac{\left(\left(\mathrm{g}_{0}\right)^{(m-1)-\chi_{b, i, k}}\right)}{(m-1)-\chi_{b, i, k}} .
$$

The central moments $\mu_{s}=\sum_{k=0}^{s}\left(\begin{array}{l}S \\ k\end{array}\right)(-1)^{k}\left(\mu_{1}^{\prime}\right)^{s} \mu_{s-k}^{\prime}$ and first four cumulants $K_{1}=\mu_{1}^{\prime}, K_{2}=\mu_{2}^{\prime}-\mu_{1}^{\prime 2}, K_{3}=\mu_{3}^{\prime}-$ $3 \mu_{2}^{\prime} \mu_{1}^{\prime}+2 \mu_{1}^{/ 3}, K_{4}=\mu_{4}^{\prime}-4 \mu_{3}^{\prime} \mu_{1}^{\prime}-3 \mu_{2}^{/ 2}+12 \mu_{2}^{\prime} \mu_{1}^{/ 2}-6 \mu_{1}^{/ 4}$ for $X$ may easily be defined by ordinary moments. To study the tail and peak behavior for $X$, a measure of skewness $\left(\beta_{1}=\mu_{3}^{2} / \mu_{2}^{3}\right)$ and measure of kurtosis $\left(\beta_{2}=\mu_{4} / \mu_{2}^{2}\right)$, play a significant role, respectively. Some numerical results of the first four ordinary moments $\left(\mu^{\prime}{ }_{1}, \mu^{\prime}{ }_{2}, \mu^{\prime}{ }_{3}, \mu^{\prime}{ }_{4}\right), \sigma^{2}=$ variance, $\beta_{1}=$ skewness, and $\beta_{2}=$ kurtosis for some choices of model parameters for $\mathrm{g}_{0}=1.3$ is presented in Table 2. 
Table 2. Some numerical results of moments, variance, skewness, and kurtosis

\begin{tabular}{|c|c|c|c|c|c|}
\hline Statistics & & & $\mathbf{a}=$ & & \\
\hline $\boldsymbol{\mu}^{\prime}{ }_{r}$ & $b=0.4$ & $b=0.5$ & $b=0.6$ & $b=0.7$ & $b=0.8$ \\
\hline$\mu_{1}^{\prime}$ & 0.3230 & 0.4024 & 0.4724 & 0.5336 & 0.5873 \\
\hline $\boldsymbol{\mu}_{2}^{\prime}$ & 0.1832 & 0.2443 & 0.3050 & 0.3637 & 0.4199 \\
\hline $\boldsymbol{\mu}_{3}^{\prime}$ & 0.1363 & 0.1861 & 0.2381 & 0.2911 & 0.3441 \\
\hline$\mu^{\prime}{ }_{4}$ & 0.1172 & 0.1617 & 0.2091 & 0.2587 & 0.3096 \\
\hline$\sigma^{2}$ & 0.0910 & 0.0992 & 0.0997 & 0.0932 & 0.0799 \\
\hline$\beta_{1}$ & 0.4279 & 0.1765 & 0.0791 & 0.0411 & 0.0274 \\
\hline$\beta_{2}$ & 1.3768 & 0.8019 & 0.4972 & 0.3126 & 0.1823 \\
\hline Statistics & $b=0.9$ & $b=0.1$ & $b=0.3$ & $b=0.1$ & $b=0.5$ \\
\hline $\boldsymbol{\mu}^{\prime}{ }_{r}$ & $a=2.01$ & $a=2.1$ & $a=1.9$ & $a=1.9$ & $a=0.9$ \\
\hline $\boldsymbol{\mu}^{\prime}{ }_{1}$ & 0.5657 & 0.0216 & 0.1791 & 0.0287 & 0.5590 \\
\hline $\boldsymbol{\mu}^{\prime}{ }_{2}$ & 0.3761 & 0.0068 & 0.0771 & 0.0103 & 0.4416 \\
\hline $\boldsymbol{\mu}_{3}^{\prime}$ & 0.2833 & 0.0037 & 0.0486 & 0.0062 & 0.4108 \\
\hline$\mu^{\prime}{ }_{4}$ & 0.2344 & 0.0027 & 0.0372 & 0.0047 & 0.4168 \\
\hline$\sigma^{2}$ & 0.0154 & 0.0061 & 0.0427 & 0.0092 & 0.1636 \\
\hline$\beta_{1}$ & 0.1807 & 39.2183 & 1.9478 & 29.3150 & 0.0049 \\
\hline$\beta_{2}$ & -0.1411 & 55.0211 & 3.7508 & 40.8929 & 0.2454 \\
\hline
\end{tabular}

We observe that the results of moments are decreasing whereas variance, skewness, and kurtosis have flexible performances at different values of $\boldsymbol{a}$ and $\boldsymbol{b}$.

\subsection{Incomplete Moments and Residual Life Function}

The $r$ - th lower incomplete moments is defined as $\Phi_{r}(x)=\int_{0}^{t} x^{r} f(x) d x$. It is obtained for $X$ as

$$
\Phi_{r-\mathrm{O} F \mathrm{LII}-P F}(x)=a b \sum_{i, j, k=0}^{\infty} B_{i, j, k} \frac{\left(t^{r-\chi_{b, i, k}}\right)}{r-\chi_{b, i, k}} .
$$

The first incomplete moment is obtained by simply substituting $r=1$ in (18) and it is given by

$$
\Phi_{1-\mathrm{O} F r \mathrm{LII}-P F}(x)=a b \sum_{i, j, k=0}^{\infty} B_{i, j, k} \frac{\left(t^{1-\chi_{b, i, k}}\right)}{1-\chi_{b, i, k}} .
$$

The residual life function is defined by $R_{t}(x)=\frac{s(x+t)}{s(t)}$. The residual life function and associated CDF of $X$ are given by

$$
\begin{gathered}
R_{t(x)-\mathrm{OFrLII}-P F}(t / x)=\frac{\left(1-e^{1-\left(\frac{\mathrm{g}_{0}}{x+t}\right)^{b}}\right)^{a}}{\left(1-e^{1-\left(\frac{\mathrm{g}_{0}}{t}\right)^{b}}\right)^{a}}, x>0 . \\
F_{R(t)-\mathrm{OFrLII}-P F}(t / x)=1-\frac{\left(1-e^{1-\left(\frac{\mathrm{g}_{0}}{x+t}\right)^{b}}\right)^{a}}{\left(1-e^{1-\left(\frac{\mathrm{g}_{0}}{t}\right)^{b}}\right)^{a}} ; x>0 .
\end{gathered}
$$

Furthermore, the reversed residual life function is defined by $\bar{R}_{t}(x)=\frac{s(x-t)}{s(t)}$. The reversed residual life function and 
associated CDF of $X$ are given by

$$
\bar{R}_{t(x)-\mathrm{OFrLII}-P F}(t / x)=\frac{\left(1-e^{1-\left(\frac{\mathrm{g}_{0}}{x-t}\right)^{b}}\right)^{a}}{\left(1-e^{1-\left(\frac{\mathrm{g}_{0}}{t}\right)^{b}}\right)^{a}}, x>0 .
$$

The mean residual life function $E\left(R_{t(x)}\right)=\frac{1}{s(t)}\left(\mu_{1, t}^{\prime}-\int_{0}^{t} x f(x) d x\right)-t ; t \geq 0$, reversed residual life function $E\left(\bar{R}_{t(x)}\right)=t-\frac{1}{F(t)} \int_{0}^{t} x f(x) d x ; t \geq 0$, and strong mean inactivity time (SMIT) $M(t)=t^{2}-\frac{1}{F(t)} \int_{0}^{t} x^{2} f(x) d x$, may easily be derived by following equations (17) and (19) and for SMIT substitute $r=2$ with (17), respectively. Furthermore, the Lorenz $L(x)$ and Bonferroni $B(x)$ curves have a significant role not only in the study of economics, the distribution of income, poverty, or wealth, but it has a vital role in fields of insurance, demography, medicine, reliability engineering, and others. The first incomplete moment is very useful in the discussion of Lorenz and Bonferroni curves and it is obtained for $X$ respectively, by

$$
\begin{aligned}
& L(x)=\frac{\int_{0}^{t} x f(x) d x}{\mu_{1}^{\prime}} \\
& B(x)=\frac{L(x)}{F(x)} \\
& \text {, and } \\
& L(x)=\frac{\sum_{i, j, k=0}^{\infty} B_{i, j, k} \frac{\left(t^{1-\chi_{b, i, k}}\right)}{1-\chi_{b, i, k}}}{\sum_{i, j, k=0}^{\infty} B_{i, j, k} \frac{\left(\left(\mathrm{g}_{0}\right)^{1-\chi_{b, i, k}}\right)}{1-\chi_{b, i, k}}} \\
& B(x)=\frac{\sum_{i, j, k=0}^{\infty} B_{i, j, k} \frac{\left(t^{1-\chi_{b, i, k}}\right)}{1-\chi_{b, i, k}}}{\sum_{i, j, k=0}^{\infty} B_{i, j, k} \frac{\left(\left(\mathrm{g}_{0}\right)^{1-\chi_{b, i, k}}\right)}{1-\chi_{b, i, k}}\left(1-\left(1-e^{1-\left(\frac{\mathrm{g}_{0}}{x}\right)^{b}}\right)^{a}\right)} .
\end{aligned}
$$

\subsection{Distribution of Order Statistics}

In reliability analysis and life testing of a component in quality control, order statistics (OS) has a noteworthy contribution. Let $X_{1}, X_{2}, X_{3}, \ldots, X_{n}$ be a random sample of size $n$ follows to the O-L-II-PF distribution and $\left\{X_{(1)}<X_{(2)}\right.$ $<X_{(3)}<\ldots<X_{(n)}$ \} be the corresponding order statistics. The PDF of $i$-th OS is given by

$$
f_{(i: n)}(x)=\frac{1}{B(i, n-i+1) !}(F(x))^{i-1}(1-F(x))^{n-i} f(x), \quad i=1,2,3, \ldots, n .
$$

By incorporating (11) and (12), $i$-th OS PDF for $X$ is given by

$$
f_{(i: n)-\mathrm{O} F \mathrm{LII}-P F}(x ; a, b)=\left(\begin{array}{c}
\frac{1}{B(i, n-i+1) !}\left(1-\left(1-e^{1-\left(\frac{\mathrm{g}_{0}}{x}\right)^{b}}\right)^{a}\right)^{i-1}\left(\left(1-e^{1-\left(\frac{\mathrm{g}_{0}}{x}\right)^{b}}\right)^{a}\right)^{n-i} \times \\
\frac{a b\left(\mathrm{~g}_{0}\right)^{b}}{x^{1+b}} e^{1-\left(\frac{\mathrm{g}_{0}}{x}\right)^{b}}\left(1-e^{1-\left(\frac{\mathrm{g}_{0}}{x}\right)^{b}}\right)^{a-1}
\end{array}\right) .
$$

Minimum OS PDF

$$
f_{(1: n)-\mathrm{O} F r \mathrm{LII}-P F}(x ; a, b)=\left(\begin{array}{c}
\frac{1}{B(i, n-i+1) !}\left(\left(1-e^{1-\left(\frac{\mathrm{g}_{0}}{x}\right)^{b}}\right)^{a}\right)^{n-1} \times \\
\frac{a b\left(\mathrm{~g}_{0}\right)^{b}}{x^{1+b}} e^{1-\left(\frac{\mathrm{g}_{0}}{x}\right)^{b}}\left(1-e^{1-\left(\frac{\mathrm{g}_{0}}{x}\right)^{b}}\right)^{a-1}
\end{array}\right),
$$

and maximum OS PDF for $X$ is given by 


$$
f_{(n: n)-\mathrm{OFrLII}-P F}(x ; a, b)=\frac{1}{B(i, n-i+1) !}\left(\begin{array}{c}
\left(1-\left(1-e^{1-\left(\frac{\mathrm{g}_{0}}{x}\right)^{b}}\right)^{a}\right)^{n-1} \times \\
\frac{a b\left(\mathrm{~g}_{0}\right)^{b}}{x^{1+b}} e^{1-\left(\frac{\mathrm{g}_{0}}{x}\right)^{b}}\left(1-e^{1-\left(\frac{\mathrm{g}_{0}}{x}\right)^{b}}\right)^{a-1}
\end{array}\right) .
$$

The $i$-th OS CDF is defined by

$$
F_{(i: n)}(x)=\sum_{r=i}^{n}\left(\begin{array}{l}
n \\
r
\end{array}\right)(F(x))^{r}(1-F(x))^{n-r}
$$

By incorporating (11), we obtain the $i$-th OS CDF for $X$ and it is given by

$$
F_{(i: n)-O F r \operatorname{LII}-P F}(x ; a, b)=\sum_{r=1}^{n}\left(\begin{array}{l}
n \\
r
\end{array}\right)\left(1-\left(1-e^{1-\left(\frac{\mathrm{g}_{0}}{x}\right)^{b}}\right)^{a}\right)^{r}\left(\left(1-e^{1-\left(\frac{\mathrm{g}_{0}}{x}\right)^{b}}\right)^{a}\right)^{n-r} .
$$

\subsection{Quantile Function}

The $q^{\text {th }}$ quantile function of the OFrLII-PF distribution is obtained by inverting the CDF. It is defined as $q=F\left(x_{q}\right)=$ $P\left(X \leq x_{q}\right), q \in(0,1)$. Then; the quantile function for $X$ is given by

$$
x_{q-\mathrm{O} F \mathrm{LII}-P F}=\frac{\mathrm{g}_{0}}{\left(1-\log \left(1-(1-q)^{1 / a}\right)\right)^{1 / b}} .
$$

To derive the $1^{\text {st }}$ quartile, median and $3^{\text {rd }}$ quartile of $X$, one may place $q=0.25,0.5$, and 0.75 respectively in (20). Henceforth, to generate random numbers, one may assume that the CDF for $X$ follows to uniform distribution $u=U(0$, 1).

\subsection{Bivariate and Multivariate Extensions}

In this sub-section, we develop the bivariate and multivariate extensions for the OFrLII-PF distribution by following the Morgenstern family and the Clayton family.

The CDF of the $\mathrm{Bi}-\mathrm{O} F r$ LII-PF distribution followed by the Morgenstern family for the random vector $\left(V_{1}, V_{2}\right)$ is

$$
F_{\phi-\mathrm{O} F \mathrm{LII}-P F}\left(V_{1}, V_{2}\right)=\left(1+\phi\left(1-F_{1}\left(v_{1}\right)\right)\left(1-F_{2}\left(v_{2}\right)\right)\right) F_{1}\left(v_{1}\right) F_{2}\left(v_{2}\right),
$$

where $|\phi| \leq 1, F_{1}\left(v_{1}\right)=1-\left(1-e^{1-\left(\frac{\mathrm{g}_{01}}{v_{1}}\right)^{b_{1}}}\right)^{a_{1}}$, and $F_{2}\left(v_{2}\right)=1-\left(1-e^{1-\left(\frac{\mathrm{g}_{02}}{v_{2}}\right)^{b_{2}}}\right)^{a_{2}}$.

The CDF of the Bi-OFrLII-PF distribution followed by the Clayton family for the random vector $(X, Y)$ is

$$
C(x, y)=\left(x^{-\left(\zeta_{1}+\zeta_{2}\right)}+y^{-\left(\zeta_{1}+\zeta_{2}\right)}-1\right)^{-\frac{1}{\left(\zeta_{1}+\zeta_{2}\right)}} ; \zeta_{1}+\zeta_{2} \geq 0 .
$$

Let $v_{1} \sim \mathrm{O}-\mathrm{O} F r$ LII-PF $\left(\alpha_{1}, \beta_{1}\right)$, and $v_{2} \sim \mathrm{O}-\mathrm{O} F r$ LII-PF $\left(\alpha_{2}, \beta_{2}\right)$. Then setting

$$
x=F_{1}\left(v_{1}\right)=1-\left(1-e^{1-\left(\frac{\mathrm{g}_{01} 1}{v_{1}}\right)^{b_{1}}}\right)^{a_{1}} \text { and } y=F_{2}\left(v_{2}\right)=1-\left(1-e^{1-\left(\frac{\mathrm{g}_{02}}{v_{2}}\right)^{b_{2}}}\right)^{a_{2}} .
$$

The CDF of the $\mathrm{Bi}-\mathrm{OF}$ LII-PF distribution followed by the Clayton family for the random vector $\left(V_{1}, V_{2}\right)$ is

A simple $n$-dimensional extension of the last version will be

$$
G_{B i-\mathrm{O} F r \mathrm{LII}-P F}\left(v_{1}, v_{2}\right)=\left(\begin{array}{l}
\left.\left(1-\left(1-e^{1-\left(\frac{\mathrm{g}_{01}}{v_{1}}\right)^{b_{1}}}\right)^{a_{1}}\right)^{\left(\zeta_{1}+\zeta_{2}\right)}+\right)^{-\frac{1}{\left(\zeta_{1}+\zeta_{2}\right)}} \\
\left(1-\left(1-e^{1-\left(\frac{\mathrm{g}_{02}}{v_{2}}\right)^{b_{2}}}\right)^{a_{2}}\right)^{\left(\zeta_{1}+\zeta_{2}\right)}-1
\end{array}\right)^{(.}
$$




$$
H\left(x_{1}, x_{2}, x_{3}, \ldots, x_{n}\right)=\left(\sum_{i=1}^{n}\left(\left(1-\left(1-e^{1-\left(\frac{\mathrm{g}_{0 i}}{x_{i}}\right)^{b_{i}}}\right)^{a_{i}}\right)^{\left(\zeta_{1}+\zeta_{2}\right)}\right)+1-n\right)^{-\frac{1}{\left(\zeta_{1}+\zeta_{2}\right)}} .
$$

\section{Inference}

In this section, we discuss an estimation technique for OFrLII-PF distribution known as the method of maximum likelihood estimation.

Let $X_{1}, X_{2}, \ldots, X_{n}$ be a random sample of size $n$ from $X$, then the likelihood function $L(\phi)=\prod_{i=1}^{n} f_{\mathrm{OF} r \mathrm{LII}-P F}\left(x_{i} ; a, b\right)$ of $X$ is given by

$$
L_{\mathrm{OFrLII}-P F}(\phi)=\frac{\left(a b\left(\mathrm{~g}_{0}\right)^{b}\right)^{n}}{\prod_{i=1}^{n} x_{i}{ }^{1+b}} \prod_{i=1}^{n} e^{1-\left(\frac{\mathrm{g}}{x_{i}}\right)^{b}} \prod_{i=1}^{n}\left(1-e^{1-\left(\frac{\mathrm{g}_{0}}{x_{i}}\right)^{b}}\right)^{a-1} .
$$

The log-likelihood function, $l_{\mathrm{OF} \text { LII-PF }}(\phi)$ of $X$ is given by

$$
\begin{gathered}
l_{O-L-I I-P F}(\phi)=n\left(\log a+\log b+b \log \left(\mathrm{g}_{0}\right)\right)-(1+b) \sum_{i=1}^{n} \log x_{i}+\sum_{i=1}^{n}\left(1-\left(\frac{\mathrm{g}_{0}}{x_{i}}\right)^{b}\right)+ \\
(a-1) \sum_{i=1}^{n} \log \left(1-e^{1-\left(\frac{\mathrm{g}_{0}}{x_{i}}\right)^{b}}\right) .
\end{gathered}
$$

The partial derivatives w.r.t $a$ and $b$ of (21) yield

$$
\frac{\partial l_{\mathrm{OFrLII}-P F}(\phi)}{\partial a}=\frac{n}{a}+\sum_{i=1}^{n} \log \left(1-e^{1-\left(\frac{\mathrm{g}_{0}}{x_{i}}\right)^{b}}\right),
$$

and

$$
\frac{\partial l_{\mathrm{OFrLII}-P F}(\phi)}{\partial b}=\frac{n}{b}-\sum_{i=1}^{n} \log x_{i}-\sum_{i=1}^{n}\left(\frac{\mathrm{g}_{0}}{x_{i}}\right)^{b} \log \left(\frac{\mathrm{g}_{0}}{x_{i}}\right)-(a-1) \sum_{i=1}^{n}\left(\frac{\left(\frac{\mathrm{g}_{0}}{x_{i}}\right)^{b} e^{1-\left(\frac{\mathrm{g}_{0}}{x_{i}}\right)^{b}} \log \left(\frac{\mathrm{g}_{0}}{x_{i}}\right)}{\left(1-e^{1-\left(\frac{\mathrm{g}_{0}}{x_{i}}\right)^{b}}\right)}\right),
$$

respectively. The maximum likelihood estimates $(\hat{\phi}=\widehat{a}, \hat{b})$ for the OFrLII-PF distribution can be obtained by maximizing (21) or by solving the prior non-linear equations simultaneously. These non-linear equations although do not provide an analytical solution for the MLEs and the optimum value of $a$, and $b$. Consequently, the Newton-Raphson type algorithm is an appropriate choice in the support of MLEs.

\subsection{Simulation Experiment}

In this sub-section, we perform a simulation experiment to observe the asymptotic performance of MLE's $\hat{\phi}=(\hat{a}, \hat{b})$. For this, we discuss the following algorithm.

Step -1. A random sample $x_{1}, x_{2}, x_{3}, \ldots, x_{n}$ of sizes $n=25,50,100,200,300,400,500$, and 1000 from (20).

Step -2. The required results are obtained based on the different combinations of the model parameters place in S-I $(a$ $=2.2, b=1.9)$, S-II $(a=3.9, b=3.1)$, S-III $(a=0.9, b=0.5)$, and S-IV $(a=0.5, b=2.1)$.

Step -3. Results of mean, variance (short Var), Bias, and root mean square error (short RMSE) are calculated with the assist of statistical software R with its exclusive function $n l m i b$. These results are presented in Tables 3 to 10 .

Step -4. Each sample is replicated $\mathrm{N}=1000$ times.

Step -5. Gradual decrease with the increase in sample sizes is observed in mean, biases, RMSEs, and Var.

Furthermore, the following measures are defined in the development of average estimate (AE), variance, bias, and RMSE, and these measures are: 


$$
\begin{aligned}
& A E=\frac{1}{N} \sum_{i=1}^{N} \hat{\phi}_{i}, \operatorname{Var}=\frac{1}{N} \sum_{i=1}^{N}\left(\phi-\bar{\phi}_{i}\right)^{2}, \text { Bias }=\frac{1}{N} \sum_{i=1}^{N}\left(\hat{\phi}_{i}-\phi\right), \\
& R M S E=\sqrt{\frac{1}{N} \sum_{i=1}^{N}\left(\hat{\phi}_{i}-\phi\right)^{2}}
\end{aligned}
$$

Table 3. Mean, Variance, Bias, and Root Mean Square Error for S-I

\begin{tabular}{lllll}
\hline Sample & Mean $_{a}$ & $\operatorname{Var}_{a}$ & Bias $_{a}$ & RMSE $_{a}$ \\
\hline 25 & 2.1081 & 0.3401 & -0.0918 & 0.5904 \\
50 & 1.9898 & 0.1323 & -0.2102 & 0.4201 \\
100 & 1.9358 & 0.0592 & -0.2641 & 0.3591 \\
200 & 1.9067 & 0.0273 & -0.2932 & 0.3366 \\
300 & 1.8995 & 0.0172 & -0.3004 & 0.3278 \\
400 & 1.8943 & 0.0131 & -0.3056 & 0.3263 \\
500 & 1.8914 & 0.0103 & -0.3085 & 0.3248 \\
1000 & 1.8860 & 0.0051 & -0.3139 & 0.3220 \\
\hline
\end{tabular}

Table 4. Mean, Variance, Bias, and Root Mean Square Error for S-I

\begin{tabular}{lllll}
\hline Sample & $\operatorname{Mean}_{b}$ & $\operatorname{Var}_{b}$ & Bias $_{b}$ & RMSE $_{b}$ \\
\hline 25 & 1.7632 & 0.0371 & -0.1367 & 0.2362 \\
50 & 1.7299 & 0.0176 & -0.1700 & 0.2157 \\
100 & 1.7162 & 0.0080 & -0.1837 & 0.2045 \\
200 & 1.7072 & 0.0043 & -0.1927 & 0.2037 \\
300 & 1.7061 & 0.0028 & -0.1938 & 0.2010 \\
400 & 1.7046 & 0.0021 & -0.1953 & 0.2007 \\
500 & 1.7034 & 0.0016 & -0.1965 & 0.2007 \\
1000 & 1.7021 & 0.0007 & -0.1978 & 0.1999 \\
\hline
\end{tabular}

Table 5. Mean, Variance, Bias, and Root Mean Square Error for S-II

\begin{tabular}{lllll}
\hline Sample & Mean $_{a}$ & $\operatorname{Var}_{a}$ & Bias $_{a}$ & RMSE $_{a}$ \\
\hline 25 & 3.3402 & 0.9733 & -0.5597 & 1.1343 \\
50 & 3.1289 & 0.3695 & -0.7710 & 0.9818 \\
100 & 3.0361 & 0.1628 & -0.8638 & 0.9534 \\
200 & 2.9858 & 0.0760 & -0.9142 & 0.9548 \\
300 & 2.9736 & 0.0476 & -0.9263 & 0.9516 \\
400 & 2.9647 & 0.0362 & -0.9352 & 0.9544 \\
500 & 2.9593 & 0.0283 & -0.9406 & 0.9555 \\
1000 & 2.9504 & 0.0140 & -0.9495 & 0.9569 \\
\hline
\end{tabular}


Table 6. Mean, Variance, Bias, and Root Mean Square Error for S-II

\begin{tabular}{lllll}
\hline Sample & Mean $_{b}$ & $\operatorname{Var}_{b}$ & Bias $_{b}$ & RMSE $_{b}$ \\
\hline 25 & 2.7772 & 0.0696 & -0.3227 & 0.4169 \\
50 & 2.7327 & 0.0333 & -0.3672 & 0.4101 \\
100 & 2.7150 & 0.0153 & -0.3849 & 0.4043 \\
200 & 2.7030 & 0.0083 & -0.3969 & 0.4073 \\
300 & 2.7017 & 0.0054 & -0.3982 & 0.4050 \\
400 & 2.6995 & 0.0041 & -0.4004 & 0.4055 \\
500 & 2.6979 & 0.0031 & -0.4020 & 0.4060 \\
1000 & 2.6962 & 0.0015 & -0.4037 & 0.4056 \\
\hline
\end{tabular}

Table 7. Mean, Variance, Bias, and Root Mean Square Error for S-III

\begin{tabular}{lllll}
\hline Sample & Mean $_{a}$ & Var $_{a}$ & Bias $_{a}$ & RMSE $_{a}$ \\
\hline 25 & 0.9572 & 0.0586 & 0.0572 & 0.2487 \\
50 & 0.9120 & 0.0235 & 0.0120 & 0.1540 \\
100 & 0.8899 & 0.0107 & -0.0101 & 0.1042 \\
200 & 0.8782 & 0.0048 & -0.0217 & 0.0731 \\
300 & 0.8751 & 0.0031 & -0.0248 & 0.0610 \\
400 & 0.8730 & 0.0024 & -0.0269 & 0.0556 \\
500 & 0.8719 & 0.0018 & -0.0280 & 0.0516 \\
1000 & 0.8696 & 0.0009 & -0.0303 & 0.0432 \\
\hline
\end{tabular}

Table 8. Mean, Variance, Bias, and RMSE for S-III

\begin{tabular}{lllll}
\hline Sample & Mean $_{b}$ & $\operatorname{Var}_{b}$ & Bias $_{b}$ & RMSE $_{b}$ \\
\hline 25 & 0.5037 & 0.0057 & 0.0037 & 0.0760 \\
50 & 0.4893 & 0.0026 & -0.0106 & 0.0526 \\
100 & 0.4827 & 0.0011 & -0.0172 & 0.0382 \\
200 & 0.4789 & 0.0006 & -0.0210 & 0.0325 \\
300 & 0.4783 & 0.0004 & -0.0216 & 0.0295 \\
400 & 0.4777 & 0.0003 & -0.0222 & 0.0282 \\
500 & 0.4772 & 0.0002 & -0.0227 & 0.0274 \\
1000 & 0.4765 & 0.0001 & -0.0234 & 0.0257 \\
\hline
\end{tabular}

Table 9. Mean, Variance, Bias, and Root Mean Square Error for S-IV

\begin{tabular}{lllll}
\hline Sample & Mean $_{a}$ & Var $_{a}$ & Bias $_{a}$ & RMSE $_{a}$ \\
\hline 25 & 0.4514 & 0.0109 & -0.0485 & 0.1155 \\
50 & 0.4365 & 0.0045 & -0.0634 & 0.0928 \\
100 & 0.4288 & 0.0021 & -0.0711 & 0.0847 \\
200 & 0.4244 & 0.0009 & -0.0755 & 0.0815 \\
300 & 0.4232 & 0.0006 & -0.0767 & 0.0805 \\
400 & 0.4225 & 0.0004 & -0.0775 & 0.0803 \\
500 & 0.4221 & 0.0003 & -0.0778 & 0.0801 \\
1000 & 0.4214 & 0.0001 & -0.0785 & 0.0796 \\
\hline
\end{tabular}


Table 10. Mean, Variance, Bias, and Root Mean Square Error for S-IV

\begin{tabular}{lllll}
\hline Sample & Mean $_{b}$ & $\operatorname{Var}_{b}$ & Bias $_{b}$ & RMSE $_{b}$ \\
\hline 25 & 1.4678 & 0.0478 & -0.6321 & 0.6688 \\
50 & 1.4323 & 0.0222 & -0.6676 & 0.6841 \\
100 & 1.4147 & 0.0105 & -0.6852 & 0.6928 \\
200 & 1.4031 & 0.0054 & -0.6968 & 0.7007 \\
300 & 1.4014 & 0.0035 & -0.6985 & 0.7010 \\
400 & 1.3996 & 0.0026 & -0.7003 & 0.7022 \\
500 & 1.3985 & 0.0021 & -0.7015 & 0.7029 \\
1000 & 1.3966 & 0.0010 & -0.7033 & 0.7040 \\
\hline
\end{tabular}

\section{Analysis of Engineering and COVID-19 Events}

In this section, we analyze three real-life data sets. These data sets are related to the engineering sector and the COVID-19 pandemic particularly outbreaks in the United Kingdom. The first data set illustrates the failure times of 50 devices put on life test at time zero discussed by [28] and explicitly, data set is: $0.1,0.2,1.0,1.0,1.0,1.0,1.0,2.0,3.0$, 6.0, 7.0, 11.0, 12.0, 18.0, 18.0, 18.0, 18.0, 18.0, 21.0, 32.0, 36.0, 40.0, 45.0, 45.0, 47.0, 50.0, 55.0, 60.0, 63.0, 63.0, 67.0, $67.0,67.0,67.0,72.0,75.0,79.0,82.0,82.0,83.0,84.0,84.0,84.0,85.0,85.0,85.0,85.0,85.0,86.0,86.0$. The second data set illustrates the lifetimes (in days) of 30 electronic devices discussed by [29] and the data set is: $0.020,0.029$, 0.034, 0.044, 0.057, 0.096, 0.106, 0.139, 0.156, 0.164, 0.167, 0.177, 0.250, 0.326, 0.406, 0.607, 0.650, 0.672, 0.676, $0.736,0.817,0.838,0.910,0.931,0.946,0.953,0.961,0.981,0.982,0.990$. The third data set represents mortality rate under COVID-19 pandemic outbreaks in United Kingdom (UK) from 1 December 2020 to 29 January 2021 [30]. The data set is: $0.1292,0.3805,0.4049,0.2564,0.3091,0.2413,0.1390,0.1127,0.3547,0.3126,0.2991,0.2428$, $0.2942,0.0807,0.1285,0.2775,0.3311,0.2825,0.2559,0.2756,0.1652,0.1072,0.3383,0.3575,0.2708,0.2649,0.0961$, $0.1565,0.1580,0.1981,0.4154,0.3990,0.2483,0.1762,0.1760,0.1543,0.3238,0.3771,0.4132,0.4602,0.3523$, $0.1882,0.1742,0.4033,0.4999,0.3930,0.3963,0.3960,0.2029,0.1791,0.4768,0.5331,0.3739,0.4015,0.3828$, $0.1718,0.1657,0.4542,0.4772,0.3402$.

The OFrLII-PF distribution is compared with its competitors (CDFs are presented in Table 11) based on some criteria called, -Log-likelihood (-LL), Akaike information criterion (AIC), along with the goodness of fit statistics Cramer-Von Mises (CM), Anderson-Darling (AD), and Kolmogorov Smirnov (KS) with its $p$-value. Some choices of descriptive statistics are presented in Table 12. Tables 13 to 15 illustrate the estimates of the parameters, standard errors (in parenthesis), and goodness of fit statistics as well. Conventionally the minimum value of goodness of fit statistics is the criteria for a better fit model that OFrLII-PF distribution eventually satisfies. Hence; we support that OFrLII-PF distribution is a better fit model among all of its well-established competitors over the engineering and COVID-19 events.

Furthermore, the empirically fitted density (a) and distribution function plots (b) Probability-Probability (c) and Kaplan-Meier survival plots (d), along with the total time on test transform (e) and box plots (f), are presented in Figures 2 to 4 , respectively. These plots provide sufficient information about the closest fit to subject data. All the numerical results are calculated with the assistance of statistical software $\mathrm{R}$ with its exclusive package AdequacyModel (https://www.r-project.org/). 
Table 11. List of competitive models CDFs

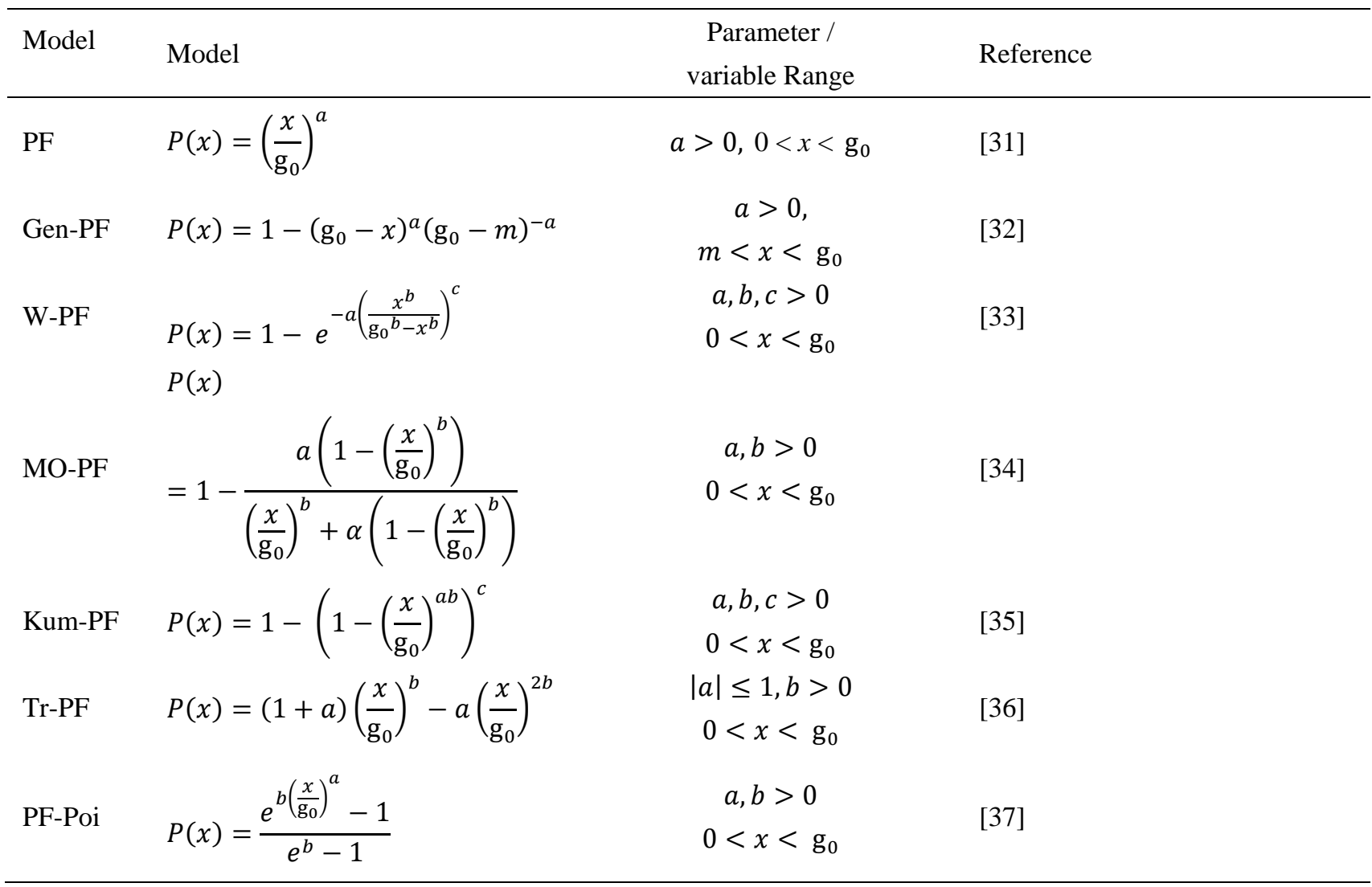

Table 12. Descriptive statistics

\begin{tabular}{lllllllll}
\hline Data set & Min & $\mathrm{Q}_{1}$ & Median & Mean & $\mathrm{Q}_{3}$ & Max & Sk & Kur \\
\hline 50 devices & 0.100 & 13.50 & 48.50 & 45.67 & 81.25 & 86.00 & -0.14 & 1.410 \\
30 devices & 0.020 & 0.143 & 0.506 & 0.494 & 0.892 & 0.990 & 0.060 & 1.310 \\
COVID-19 & 0.0807 & 0.176 & 0.288 & 0.288 & 0.385 & 0.533 & 0.047 & 1.961 \\
\hline
\end{tabular}

Table 13. Parameter estimates, standard errors (in parenthesis), and goodness of fit statistics for failure times of 50 devices data

\begin{tabular}{|c|c|c|c|c|c|c|c|c|}
\hline Model & $\hat{a}$ & $\hat{b}$ & $\hat{c}$ & $-\mathrm{LL}$ & AIC & $\mathrm{CM}$ & $\mathrm{AD}$ & $\begin{array}{l}\text { K-S } \\
\text { (p-value) }\end{array}$ \\
\hline $\mathrm{O} F r \mathrm{LII}-\mathrm{PF}$ & $\begin{array}{l}0.3585 \\
(0.0536)\end{array}$ & $\begin{array}{l}0.2183 \\
(0.0327)\end{array}$ & - & 200.4441 & 404.8882 & 0.0480 & 0.3715 & $\begin{array}{l}0.07779 \\
(0.9227)\end{array}$ \\
\hline MO-PF & $\begin{array}{l}7.6657 \\
(5.7076)\end{array}$ & $\begin{array}{l}0.2558 \\
(0.1544)\end{array}$ & - & 212.5529 & 429.1057 & 0.1179 & 0.8264 & $\begin{array}{l}0.1739 \\
(0.0969)\end{array}$ \\
\hline PF-Poi & $\begin{array}{l}2.1129 \\
(0.9889)\end{array}$ & $\begin{array}{l}0.4589 \\
(0.1468)\end{array}$ & - & 216.0639 & 436.1277 & 0.0661 & 0.5192 & $\begin{array}{l}0.2091 \\
(0.0259)\end{array}$ \\
\hline $\mathrm{Tr}-\mathrm{PF}$ & $\begin{array}{l}-0.4479 \\
(0.2411)\end{array}$ & $\begin{array}{l}0.6009 \\
(0.1233)\end{array}$ & - & 218.0597 & 440.1195 & 0.0522 & 0.4295 & $\begin{array}{l}0.2194 \\
(0.0162)\end{array}$ \\
\hline
\end{tabular}




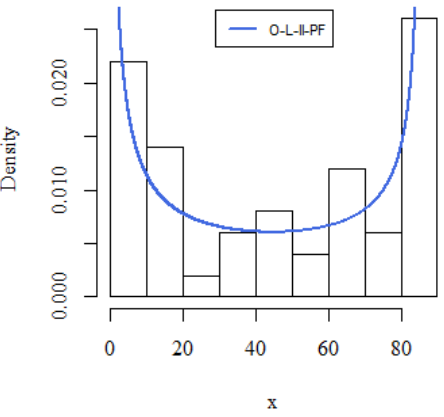

(a)

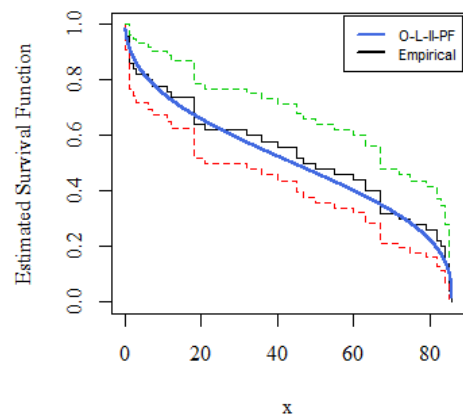

(d)

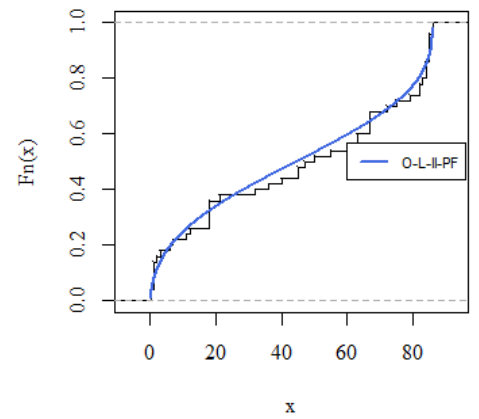

(b)

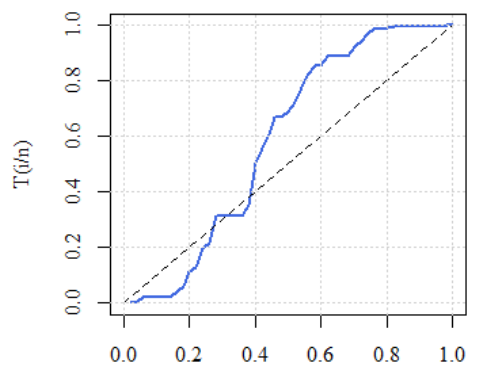

(e)

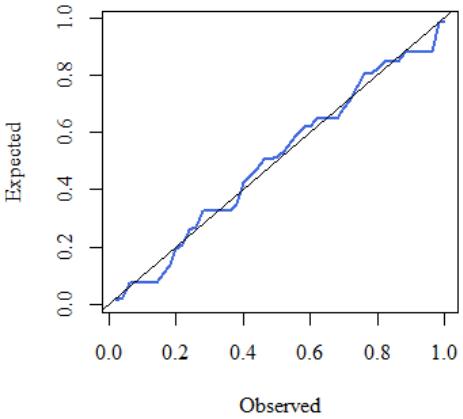

(c)

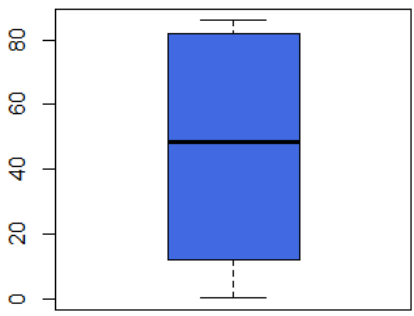

(f)

Figure 2. Fitted Plots for failure times of 50 devices data

Table 14. Parameter estimates, standard errors (parenthesis), and goodness of fit statistics for lifetimes (in days) of 30 electronic devices data

\begin{tabular}{|c|c|c|c|c|c|c|c|c|}
\hline Model & $\hat{a}$ & $\hat{b}$ & $\hat{c}$ & $-\mathrm{LL}$ & AIC & $\mathrm{CM}$ & $\mathrm{AD}$ & $\begin{array}{l}\text { K-S } \\
\text { (p-value) }\end{array}$ \\
\hline $\mathrm{O} F r$ LII-PF & $\begin{array}{l}0.4968 \\
(0.0978)\end{array}$ & $\begin{array}{l}0.3334 \\
(0.0568)\end{array}$ & - & -6.1325 & -8.2650 & 0.0713 & 0.4338 & $\begin{array}{l}0.1368 \\
(0.5802)\end{array}$ \\
\hline Kum-PF & $\begin{array}{l}7.9804 \\
(126.37)\end{array}$ & $\begin{array}{l}0.0713 \\
(1.1292)\end{array}$ & $\begin{array}{l}0.5807 \\
(0.1262)\end{array}$ & -4.3578 & -2.7157 & 0.1002 & 0.6206 & $\begin{array}{l}0.1616 \\
(0.3731)\end{array}$ \\
\hline Gen-PF & $\begin{array}{l}0.7525 \\
(0.1373)\end{array}$ & - & - & -1.9424 & -1.8849 & 0.0783 & 0.4680 & $\begin{array}{l}0.2728 \\
(0.0183)\end{array}$ \\
\hline MO-PF & $\begin{array}{l}2.5015 \\
(1.8981)\end{array}$ & $\begin{array}{l}0.5305 \\
(0.2620)\end{array}$ & - & -1.6694 & 0.6611 & 0.1212 & 0.7603 & $\begin{array}{l}0.1894 \\
(0.2038)\end{array}$ \\
\hline PF-Poi & $\begin{array}{l}0.9523 \\
(1.1370)\end{array}$ & $\begin{array}{l}0.6597 \\
(0.2397)\end{array}$ & - & -1.2320 & 1.5359 & 0.1118 & 0.6983 & $\begin{array}{l}0.1803 \\
(0.2515)\end{array}$ \\
\hline $\mathrm{Tr}-\mathrm{PF}$ & $\begin{array}{l}-0.2277 \\
(0.3731)\end{array}$ & $\begin{array}{l}0.7396 \\
(0.2037)\end{array}$ & - & -1.0026 & 1.9947 & 0.1068 & 0.6643 & $\begin{array}{l}0.1891 \\
(0.2055)\end{array}$ \\
\hline PF-I & $\begin{array}{l}0.8198 \\
(0.1496)\end{array}$ & - & - & -0.7829 & 0.4340 & 0.1021 & 0.6332 & $\begin{array}{l}0.1960 \\
(0.1741)\end{array}$ \\
\hline
\end{tabular}




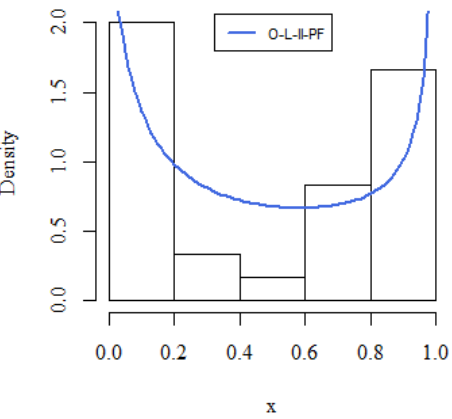

(a)

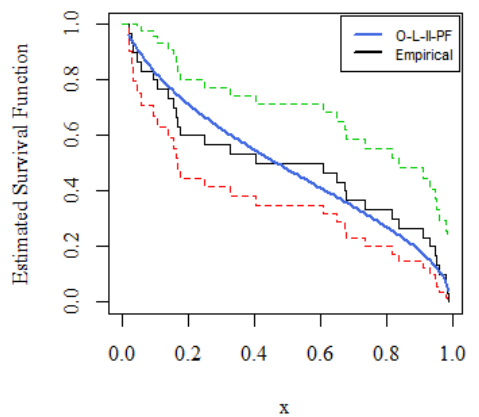

(d)

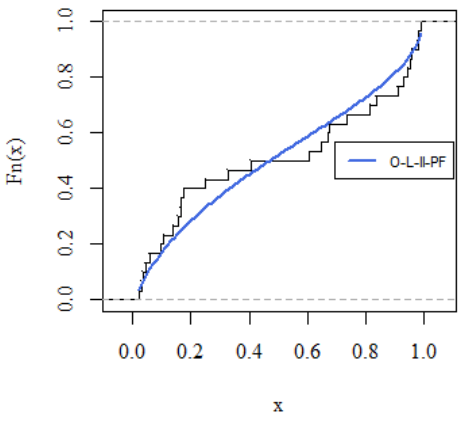

(b)

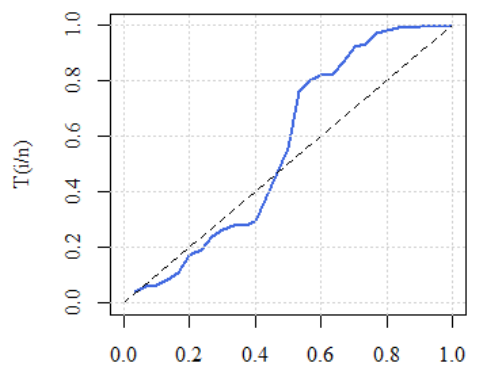

(e)

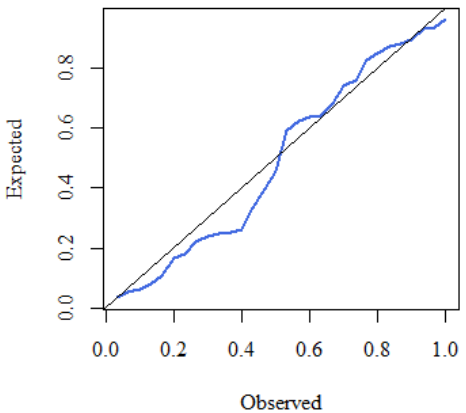

(c)

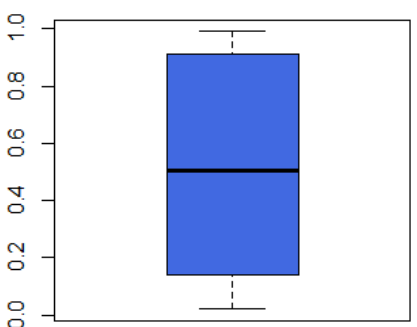

(f)

Figure 3. Fitted plots for lifetimes (in days) of 30 electronic devices data

Table 15. Parameter estimates, standard errors (parenthesis), and goodness of fit statistics for mortality rate data under COVID-19 in UK

\begin{tabular}{rllllllll}
\hline \multirow{2}{*}{ Model } & $\hat{a}$ & $\hat{b}$ & $\hat{c}$ & -LL & AIC & CM & AD & $\begin{array}{l}\text { K-S } \\
(\mathrm{p} \text {-value })\end{array}$ \\
\cline { 2 - 8 } OFrLII-PF & 1.2260 & 0.9217 & & -48.1722 & -92.3444 & 0.0743 & 0.4286 & $\begin{array}{l}0.0760 \\
(0.8524)\end{array}$ \\
& $(0.1850)$ & $(0.0766)$ & & & & & & 0.0901 \\
MO-PF & 0.1860 & 2.8671 & & -47.0925 & -90.1851 & 0.0871 & 0.5176 & $(0.6813)$ \\
& $(0.0797)$ & $(0.4567)$ & & & & & & 0.1027 \\
W-PF & 10.9575 & 1.5807 & 1.4814 & -46.2305 & -86.4610 & 0.0830 & 0.5201 & $(0.5175)$ \\
\hline
\end{tabular}




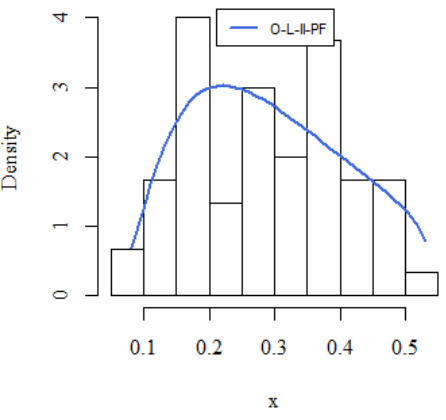

(a)

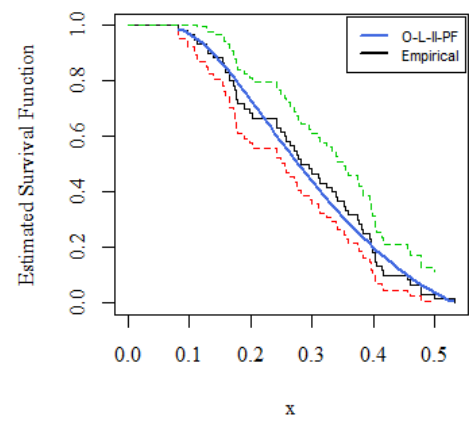

(d)

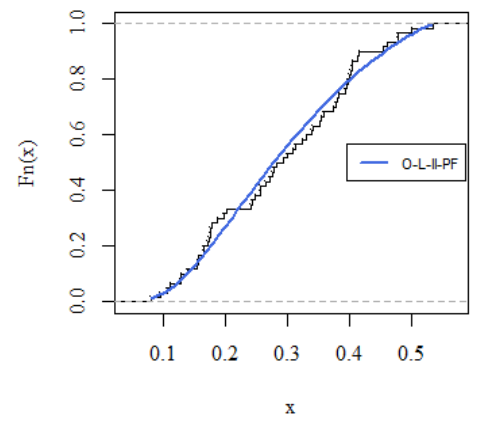

(b)

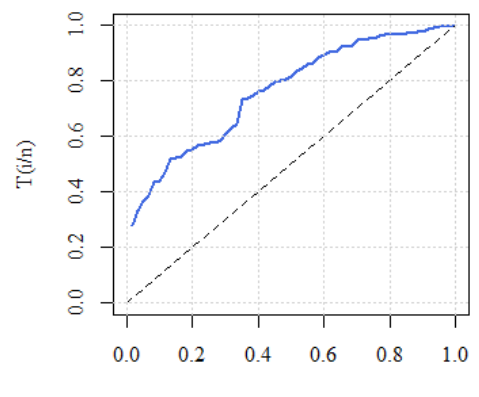

i/n

(e)

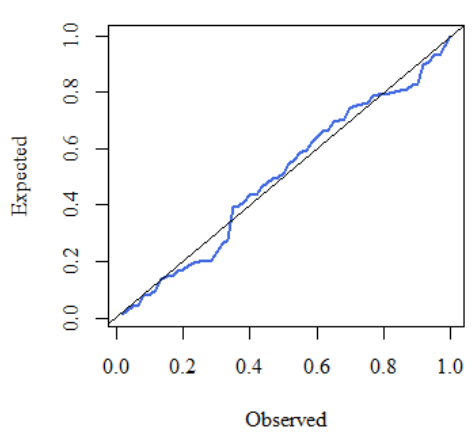

(c)

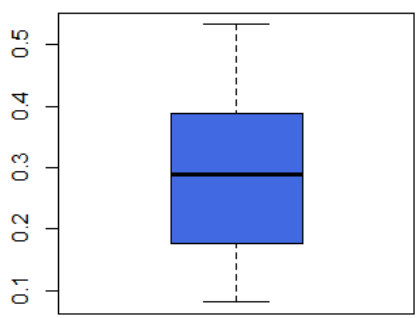

(f)

Figure 4. Fitted plots for the United Kingdom COVID-19 dat

\section{Conclusion}

This paper proposed a new family that generates flexible models in terms of PDF and HRF. It is referred to as odd Fréchet Lehmann type-II (OFrLII) G family of distributions. Several general characteristics of the proposed family and its sub-model (OFrLII-PF) are discussed in detail. Furthermore. OFrLII-PF distribution explored flexible shapes of PDF, including left-skewed, right-skewed, symmetric, or bathtub shaped, and HRF possessed U-shaped, increasing, or bathtub shaped. Applicability of OFrLII-PF distribution was explored over the engineering and COVID-19 pandemic events. Finally, closed-form PDF, CDF, and HRF of OFrLII-PF distribution attract researchers to opt for the model for forecasting and prediction resolution. Furthermore, it has outperformed estimates, and closest fit to datasets of interest expect to consider it as a better alternative than the PF distribution .

Availability of data and materials: The data supporting our findings have been attached as Additional files.

Funding: The study did not receive any funding in any form.

Acknowledgment: The authors would like to thank the Editorial Board and the referees for their valuable comments and suggestions which improved the final version of the manuscript.

Conflicts of Interest: There are no conflicts of interest for any of the authors.

Author contributions: Alya Al Mutairi: Data analysis, Interpretations, Resources, Supervision, Writing-review, and Editing; Muhammad Z. Arshad: Conceptualization; Writing-original draft preparation, Supervision, Writing-review, and Editing.

\section{References}

Aarset, M. V. (1987). How to identify a bathtub hazard rate. IEEE Transactions on Reliability, 36(1), 106-108. https://doi.org/10.1109/TR.1987.5222310 
Al Mutairi Alya, O. (2017). Pak. J. Statist. 2017 Vol. 33 (6), 491-498 TRANSMUTED WEIGHTED POWER FUNCTION DISTRIBUTIONS: PROPERTIES AND APPLICATIONS. Pak. J. Statist, 33(6), 491-498.

Al Mutairi, A., Iqbal, M. Z., Arshad, M. Z., Alnssyan, B., Al-Mofleh, H., \& Afify, A. Z. (2021). A New Extended Model with Bathtub-Shaped Failure Rate: Properties, Inference, Simulation and Applications. Mathematics, 9(17), 2024. https://doi.org/10.3390/math9172024

Alizadeh, M., Cordeiro, G. M., De Brito, E., \& Demétrio, C. G. B. (2015). The beta Marshall-Olkin family of distributions. Journal of Statistical Distributions and Applications, 2(1), 1-18. https://doi.org/10.1186/s40488-015-0027-7

Arshad, M. Z., Iqbal, M. Z., \& Al Mutairi, A. (2021). Statistical Properties of a New Bathtub Shaped Failure Rate Model With Applications in Survival and Failure Rate Data. International Journal of Statistics and Probability, 10(3), 1-49. https://doi.org/10.5539/ijsp.v10n3p49

Arshad, M. Z., Iqbal, M. Z., Anees, A., Ahmad, Z., \& Balogun, O. S. (2021). A NEW BATHTUB SHAPED FAILURE RATE MODEL: PROPERTIES, AND APPLICATIONS TO ENGINEERING SECTOR. Pakistan Journal of Statistics, 37(1).

Aslam, M., Ley, C., Hussain, Z., Shah, S. F., \& Asghar, Z. (2020). A new generator for proposing flexible lifetime distributions and its properties. PloS one, 15(4), e0231908. https://doi.org/10.1371/journal.pone.0231908

Balogun, O. S., Iqbal, M. Z., Arshad, M. Z., Afify, A. Z., \& Oguntunde, P. E. (2021). A new generalization of Lehmann type-II distribution: Theory, simulation, and applications to survival and failure rate data. Scientific African, 12, e00790. https://doi.org/10.1016/j.sciaf.2021.e00790

Bourguignon, M., Silva, R. B., \& Cordeiro, G. M. (2014). The Weibull-G family of probability distributions. Journal of data science, 12(1), 53-68. https://doi.org/10.6339/JDS.201401_12(1).0004

Butt, N. S., ul Haq, M. A., Usman, R. M., \& Fattah, A. A. (2016). Transmuted power function distribution. Gazi University Journal of Science, 29(1), 177-185.

Cordeiro, G. M., \& de Castro, M. (2011). A new family of generalized distributions. Journal of statistical computation and simulation, 81(7), 883-898. https://doi.org/10.1080/00949650903530745

Cordeiro, G. M., Ortega, E. M., \& da Cunha, D. C. (2013). The exponentiated generalized class of distributions. Journal of data science, 11(1), 1-27. https://doi.org/10.6339/JDS.2013.11(1).1086

Elbatal, I., Ahmad, Z., Elgarhy, M., \& Almarashi, A. M. (2018). A new alpha power transformed family of distributions: properties and applications to the Weibull model. Journal of Nonlinear Science and Applications, 12(1), 1-20. https://doi.org/10.22436/jnsa.012.01.01

Eugene, N., Lee, C., \& Famoye, F. (2002). Beta-normal distribution and its applications. Communications in Statistics-Theory and methods, 31(4), 497-512. https://doi.org/10.1081/STA-120003130

Gleaton, J. U., \& Lynch, J. D. (2006). Properties of generalized log-logistic families of lifetime distributions. Journal of Probability and Statistical Science, 4(1), 51-64.

Gupta, R. C., Gupta, P. L., \& Gupta, R. D. (1998). Modeling failure time data by Lehman alternatives. Communications in Statistics-Theory and methods, 27(4), 887-904. https://doi.org/10.1080/03610929808832134

Hassan, A. S., \& Assar, S. M. (2021). A new class of power function distribution: Properties and applications. Annals of Data Science, 8(2), 205-225. https://doi.org/10.1007/s40745-019-00195-7

Ibrahim, M. (2017). The Kumaraswamy power function distribution. J. Stat. Appl. Probab, 6, 81-90. https://doi.org/10.18576/jsap/060107

Ijaz, M., Asim, S. M., Farooq, M., Khan, S. A., \& Manzoor, S. (2020). A Gull Alpha Power Weibull distribution with applications to real and simulated data. Plos one, 15(6), e0233080. https://doi.org/10.1371/journal.pone.0233080

Kumar, D., Singh, U., \& Singh, S. K. (2015). A method of proposing new distribution and its application to Bladder cancer patients data. J. Stat. Appl. Pro. Lett, 2(3), 235-245.

Lehmann, E. L. (1953). The power of rank tests. The Annals of Mathematical Statistics, 23-43. https://doi.org/10.1214/aoms/1177729080

Lutful Kabir, A. B. M., \& Ahsanullah, M. (1974). Estimation of the location and scale parameters of a power-function distribution by linear functions of order statistics. Communications in Statistics-Theory and Methods, 3(5), 463-467. https://doi.org/10.1080/03610917408548393 
Mahdavi, A., \& Kundu, D. (2017). A new method for generating distributions with an application to exponential distribution. Communications in Statistics-Theory and Methods, 46(13), 6543-6557. https://doi.org/10.1080/03610926.2015.1130839

Marshall, A. W., \& Olkin, I. (1997). A new method for adding a parameter to a family of distributions with application to the exponential and Weibull families. Biometrika, 84(3), 641-652. https://doi.org/10.1093/biomet/84.3.641

Okorie, K., Akpanta, A. C., \& Ohakwe, J. (2017). Marshall-Olkin extended power function distribution. European Journal of Statistics and Probability, 5(3), 16-29.

Rahman, M. M., Al-Zahrani, B., Shahbaz, S. H., \& Shahbaz, M. Q. (2019). Cubic transmuted uniform distribution: An alternative to beta and Kumaraswamy distributions. European Journal of Pure and Applied Mathematics, 12(3), 1106-1121. https://doi.org/10.29020/nybg.ejpam.v12i3.3410

Rényi, A. (1961, January). On measures of entropy and information. In Proceedings of the Fourth Berkeley Symposium on Mathematical Statistics and Probability, Volume 1: Contributions to the Theory of Statistics (pp. 547-561). University of California Press.

Ristić, M. M., \& Balakrishnan, N. (2012). The gamma-exponentiated exponential distribution. Journal of statistical computation and simulation, 82(8), 1191-1206. https://doi.org/10.1080/00949655.2011.574633

Saran, J., \& Pandey, A. (2004). Estimation of parameters of a power function distribution and its characterization by k-th record values. Statistica, 64(3), 523-536.

Shaw, W. T., \& Buckley, I. R. (2009). The alchemy of probability distributions: beyond Gram-Charlier expansions, and a skew-kurtotic-normal distribution from a rank transmutation map. arXiv preprint arXiv:0901.0434.

Tahir, M. H., Alizadeh, M., Mansoor, M., Cordeiro, G. M., \& Zubair, M. (2016). The Weibull-power function distribution with applications. Hacettepe Journal of Mathematics and Statistics, 45(1), 245-265. https://doi.org/10.15672/HJMS.2014428212

Tahir, M. H., Cordeiro, G. M., Alzaatreh, A., Mansoor, M., \& Zubair, M. (2016). The logistic-X family of distributions and its applications. Communications in statistics-Theory and methods, 45(24), 7326-7349. https://doi.org/10.1080/03610926.2014.980516

Tahir, M. H., Hussain, M. A., Cordeiro, G. M., El-Morshedy, M., \& Eliwa, M. S. (2020). A new Kumaraswamy generalized family of distributions with properties, applications, and bivariate extension. Mathematics, 8(11), 1989. https://doi.org/10.3390/math8111989

ul Haq, M. A., Elgarhy, M., Hashmi, S., Ozel, G., \& ul Ain, Q. (2018). Transmuted Weibull power function distribution: Its properties and applications. Journal of Data Science, 16(2), 397-418. https://doi.org/10.6339/JDS.201804_16(2).0009

World Health Organization. (2021). Background document on the AZD1222 vaccine against COVID-19 developed by Oxford University and AstraZeneca: background document to the WHO Interim recommendations for use of the AZD1222 (ChAdOxl-S [recombinant]) vaccine against COVID19 developed by Oxford University and AstraZeneca, $\quad 1 \quad$ March 2021 (No. WHO/2019-nCoV/vaccines/SAGE_recommendation/AZD1222/background/2021.2). World Health Organization.

Zaka, A., Akhter, A., \& Jabeen, R. (2020). Beta Lehmann-2 Power function distribution with Application to Bladder Cancer Susceptibility and Failure Times of Air Conditioned System. Authorea Preprints. https://doi.org/10.17485/IJST/v13i23.178

\section{Copyrights}

Copyright for this article is retained by the author(s), with first publication rights granted to the journal.

This is an open-access article distributed under the terms and conditions of the Creative Commons Attribution license (http://creativecommons.org/licenses/by/4.0/). 